\title{
A PÓS-GRADUAÇÃO STRICTO SENSU EM DIREITO: UM OLHAR A PARTIR DAS FICHAS DE AVALIAÇÕES DAS TRIENAIS DE 2010 E 2013 SOBRE O QUESITO DA PRODUÇÃO INTELECTUAL
}

\author{
STRICTO SENSU POS-GRADUATION IN LAW: A LOOK FROM THE 2010 AND 2013 \\ TRIENNIAL ASSESSMENT SHEETS ON THE INTELLECTUAL PRODUCTION
}

Orides Mezzaroba

\begin{abstract}
Professor dos Programas de Graduação e Pós-Graduação em Direito (Mestrado e Doutorado) da Universidade Federal de Santa Catarina. Coordenador do Programa de Mestrado Profissional em Direito da Universidade Federal de Santa Catarina. Pesquisador de Produtividade do CNPq. E-mail: oridesmezza@gmail.com

Emerson Antonio Maccari

Professor dos Programas de Graduação e Pós-Graduação em Administração (mestrado e doutorado) da Universidade Nove de Julho. Diretor do Programa de Pós-Graduação em Administração da Universidade Nove de Julho. Pesquisador de Produtividade do CNPq.

Email: emersonmaccari@gmail.com
\end{abstract}

Recebido em: 15/05/2017

Aprovado em: 13/07/2017

Doi: $10.5585 /$ rdb.v17i7.731

RESUMO: Considerando que a transparência e a previsibilidade dos critérios de avaliação representam os principais instrumentos de planejamento para o fortalecimento dos Programas de Pós-graduação stricto sensu em Direito do Brasil, objetiva-se analisar esses elementos aplicados nas avaliações trienais de 2010 e 2013 no que diz respeito ao quesito da produção intelectual para a área do Direito junto à CAPES. Para tanto, parte-se da construção do conceito de avaliação, da função institucional da CAPES, da análise dos critérios qualitativos aplicados para a definição das métricas quantitativas da produção intelectual docente dos Programas de Pós-graduação em Direito credenciados pela CAPES. Diante dessa abordagem conclui-se pela falta de clareza nas métricas, na objetividade, na clareza, na previsibilidade e na transparência nas conclusões qualitativas sobre o impacto da produção intelectual da área do Direito nas duas avaliações trienais estudadas.

Palavras-chave: Avaliação; CAPES; Produção Intelectual; Pesquisa no Direito.

ABSTRACT: Considering that the transparency and the predictability of the evaluation criteria are the main planning instruments for the strengthening of Law Master and Doctoral Programs in Brazil, this article aims to analyze these elements applied during the CAPES triennial evaluations of 2010 and 2013 with respect to the intellectual production issue for the area of Law. To do so, we start defining the term "evaluation", the institutional function of CAPES, and analyzing the qualitative criteria applied for the definition of the quantitative metrics of the intellectual production of the Law Programs accredited by CAPES. Our results evidenced a lack of clarity in the metrics, objectivity, clarity, predictability and transparency in the qualitative conclusions 
about the impact of the intellectual production of Law discipline in the two triennial evaluations studied.

Keywords: Assessment; CAPES; Intellectual Production; Legal Research.

SUMÁRIO: Introdução. 1. O Critério Qualitativo em Processo de Avaliação. 2. A Institucionalização do CAPES enquanto Órgão de Fomento e de Controle. 3. Os Instrumentos Aplicados no Sistema de Avaliação do CAPES. 4. Critérios e Resultados das Avaliações Trienais de 2010 e 2013 aplicados no Quesito de Produção Intelectual. 4.1. Classificação de Periódicos. 4.2. Classificação de Livros, Capítulos de Livros e Coletâneas. Conclusão. Referências Bibliográficas.

\section{INTRODUÇÃO}

O presente artigo irá tratar de temática que envolve a Pós-Graduação em Direito stricto sensu, mais especificamente sobre os critérios aplicados nas avaliações trienais ocorridas nos anos de 2010 (que englobou os anos 2007, 2008 e 2009) e do ano de 2013 (relativo aos anos 2010, 2011 e 2012). A análise será delimitada sobre os dados referentes ao quesito da produção intelectual do corpo permanente dos Programas de Mestrado e Doutorado na área do Direito. O problema que envolverá a presente reflexão será o de verificar se os critérios qualitativos aplicados pela área do Direito na classificação que justificam a pontuação da produção intelectual do corpo permanente dos Programas de Mestrado e Doutorado refletem ou não o resultado quantitativo consolidados nos relatórios finais das avaliações trienais de 2010 e 2013.

A opção pela abordagem qualitativa decorre da possiblidade de se analisar o objeto de pesquisa a partir de critérios mais amplos; porém, claros, bem definidos e detalhados sobre o fenômeno que será estudado. Pela abordagem qualitativa será possível verificar se os critérios utilizados para a quantificação do resultado das avaliações representam ou não o conjunto de requisitos estabelecidos entre os atores envolvidos em todo processo avaliado.

A presente pesquisa se justificativa na medida em que a partir desses dados professores e coordenadores dos Programas de Pós-Graduação poderão estabelecer estratégias em condições de fortalecerem a produção intelectual e, consequentemente, o fortalecimento de seus cursos.

Por isso, é importante destacar que toda avaliação deve refletir a realidade de determinado conjunto que será avaliado, sendo que o sistema de avaliação deve prezar pela clareza, transparência, objetividade e participação ativa de todos os atores envolvidos. Com esses pressupostos respeitados, os gestores dos Programas de Pós-Graduação estarão seguros para estabelecerem procedimentos administrativos internos de objetivos, metas e de ações que possam garantir a previsibilidade de desenvolvimento de seus cursos em futuras avaliações. Vale destacar que o princípio fundamental da avaliação não deve ser o de se sustentar em torno do critério da punibilidade, fechada e carrega uma noção de castigo, usada para vigiar e punir, segundo o "Panóptico" de Foucault (1983). Para torná-la eficiente, é preciso que sua função - antes restrita ao controle - transforme-se em um processo mais amplo, que passe pela coleta, tratamento e disseminação de informações, as quais possam contribuir de forma dinâmica, aberta e construtiva para a tomada de decisões (UNESCO, 1998).

O espírito da avaliação deve se voltar para a verificação se as metas e as ações previamente estabelecidas foram ou não executadas adequadamente. Daí a necessidade de se estabelecer regras claras a priori, ou seja, antes do início do ciclo de avaliação (hoje quadriênio) e, garantir que elas sejam estáveis no decorrer do período objeto da avaliação.

A partir desses propósitos, o texto foi estruturado a partir da definição que caracterizam os fundamentos da avaliação qualitativa e o seu impacto sobre a avaliação quantitativa. O texto irá tratar de informações históricas e legais que possibilitaram a institucionalização da CAPES, 
bem como o seu comprometimento com a elaboração de políticas públicas de desenvolvimento, de controle e de fortalecimento do sistema de Pós-Graduação brasileiro. Na sequência, será realizada a análise dos instrumentos de avaliação disponibilizados e aplicados pela CAPES no processo das avaliações trienais de 2010 e 2013. Por fim, serão verificados os dados e as conclusões contidos nos dois relatórios de avaliações da área do Direito, a partir do recorte da produção intelectual do corpo docente permanente dos Programas de Pós-Graduação em Direito brasileiros.

\section{O CRITÉRIO QUALITATIVO EM PROCESSOS DE AVALIAÇÃO}

Avaliar significa verificar de forma periódica e sistemática as informações prestadas pelo avaliado no sentido de constatar se houve ou não algum tipo de evolução e, a partir dessas informações, identificar eventuais desajustes ou problemas para que as suas causas sejam sanadas. A qualidade de um processo de avaliação não está propriamente nos requisitos ou critérios formais. A qualidade deve estar em seus agentes que alimentam o sistema. Em regra, a falta de qualidade dos agentes avaliados pode comprometer a qualidade do sistema.

O processo de avaliação deve refletir quantitativamente a qualidade dos agentes ou de seus produtos a partir de critérios claros e objetivos. Conforme Maccari e Nishimura (2014, p. 606) o "sistema de avaliação somente poderá contribuir efetivamente" para o fortalecimento institucional se houver o entendimento argumentativo entre as partes envolvidas dos "tipos de evidências a serem aceitas e clareza nos objetivos do sistema a ser desenvolvido". Caso contrário, o sistema poderá refletir apenas uma perspectiva unilateral de quem está no espaço privilegiado da tomada de decisões.

O sistema de avaliação deve se sustentar em torno de dois pressupostos básicos: "universalização do acesso e equidade" e na medição da qualidade do produto com a utilização de "indicadores de qualidade". O papel fundamental de um sistema de avaliação está no acompanhamento do sistema de pós-graduação como um todo e não, excessivamente na produção de pesquisa, muito embora deva fomentar o seu fortalecimento em termos qualitativos. Por sua vez, os "indicadores não podem ser confundidos com as causas dos fenômenos a que eles se referem". No momento em que os indicadores são escolhidos se deve levar em consideração as "variáveis mensuráveis que tenham mostrado associação com o que se pretende medir, sem nenhuma pretensão de eleger, ao mesmo tempo, as causas responsáveis pelos resultados encontrados" (GOMES NETO; ROSENBERG, 1995, pp. 13-14). Nesse sentido, a produção de pesquisa deve ser o produto de um conjunto de resultados (desempenho docente, formação discente e impacto social do programa) e não um fim em si mesmo.

Para Cimadon (2008, p. 190), "se a ciência é a orientação fundamental da avaliação, então é lícito afirmar que não se pode fazer qualquer espécie de avaliação sem critérios que lhe deem suporte". O processo de avaliação requer a "atribuição de símbolos a fenômenos com o objetivo de caracterizar o valor do fenômeno, em geral com referência a um padrão de natureza cultural, social ou científica". Portanto, a avaliação é um processo "de delinear, obter e fornecer informações úteis para o julgamento nas tomadas de decisões ou redirecionamento de atitudes, comportamentos ou ações". A partir desse raciocínio, pode-se concluir que a avaliação se apresenta com "funções específicas, modalidades especiais e etapas construtivas". A avaliação se apresenta como uma verificação sobre dados e informações que possibilite a constatação se os propósitos estabelecidos previamente estão ou não sendo atingidos. Na medida em que a avaliação reúne dados consistentes "para uma adequada conclusão ou descrição, ela alcança mais e melhor seus propósitos".

O pressuposto básico de qualquer sistema de avaliação é o de "acompanhar os resultados alcançados, tanto no que se refere às metas como aos padrões. Por meio de indicadores que afiram essas quantidades, o sistema de avaliação permitirá o planejamento com o observado e, a 
partir disso, constatar ou não a eficiência e a eficácia da política [...] adotada”. Daí pode-se definir o sistema de avaliação "como a comparação entre os resultados observados e os desejados". Com essa comparação é que se pode "levantar hipóteses para atribuir causas aos efeitos encontrados". Porém, para que os objetivos do sistema de avaliação sejam cumpridos de forma efetiva é necessário que todas as informações sejam atuais, fidedignas e transparentes. A rapidez e a precisão "com que o sistema fornece essas informações para os [gestores e] responsáveis pelas políticas [públicas] é primordial, sob pena de reportar uma situação que não existe mais". Enfim, o sistema de avaliação deve proporcionar o levantamento de dados e informações que possibilitem a orientação de políticas públicas com o propósito de aperfeiçoar e dar consistência na melhoria da qualidade das pesquisas no país. A principal meta da avaliação deve estar "relacionada com os pressupostos do sistema, ou seja, com a verificação se esses pressupostos estão ou não sendo respeitados" (GOMES NETO; ROSENBERG, 1995, pp. 12-13).

Verhine e Freitas (2012, pp. 16-18) afirmam com convicção que não é possível "compreender as transformações da educação, no âmbito da globalização e da internacionalização do ensino superior, sem levar em conta as práticas da avaliação". Para que haja efetiva internacionalização em redes a avaliação passa a ser um instrumento imprescindível para países e governos. Só com a avaliação é possível construir parâmetros de comparações entre realidades distintas "numa perspectiva de que a compreensão dos processos educativos passe, necessariamente, pela sua inserção num contexto mais amplo". Os autores destacam ainda que pelo fato da avaliação ter como objeto "uma realidade dinâmica e complexa", é necessário que a mesma também seja considerada "polissêmica e plurirreferencial, visto que atribuir valor absoluto de verdade e objetividade" aos dados quantitativos e, seus critérios de "seleção e classificação é querer esconder o fato de que toda realidade social" é contaminada por "valores, interesses e conflitos próprios".

Para Gomes Neto e Rosenberg (1995, p. 14), “dependendo do desenho do sistema nacional de avaliação, as informações produzidas por ele permitirão comparar resultados", entre programas de pós-graduação, regiões do país, métodos e desenvolvimento de pesquisas, inserção de alunos egressos, impacto da produção científica dos pesquisadores, além de outros quesitos "bem como sinalizar situações mais problemáticas que poderão ser alvo de uma política especial". A partir da identificação dos problemas "será possível agir prontamente e utilizar estratégias com endereço certo, que resultem na solução do problema observado". O impacto sobre a economia de tempo e recursos será substancial na medida em que a precisão das correções levará em conta dados previamente diagnosticados. Os relatórios com os resultados das avaliações devem ser claros, precisos e objetivos. Todos os "resultados mais relevantes devem ser enfatizados, através de uma linguagem apropriada à clientela, em que ressaltem concisão e clareza". Enfim, os resultados da avaliação devem ser de conhecimento de todos os atores (coordenadores, professores e discentes) envolvidos no processo.

Vale destacar que mesmo que toda a avaliação tenha por objetivo tentar a "melhoria institucional, individual e coletiva através de práticas de colegialidade", não se pode ter a convicção de que a "verificação e o controle externo" possam garantir a permanente melhoria e qualidade de qualquer programa de pós-graduação ou Instituição de ensino (VERHINE; FREITAS, 2012, p. 25). As avaliações institucionais ocorrem praticamente sob duas formas: interna e externa. A avaliação interna, ou também auto-avaliação, está voltada para a análise de procedimentos e comportamentos internos da instituição. Com o objetivo de corrigir eventuais problemas no seu interior, daí a necessidade de se construir instrumentos que possibilitem a ampla e democrática participação de todos os envolvidos. No âmbito de uma instituição, a avaliação interna acaba impactando mais em transformações qualitativas. Por sua vez, a avaliação externa opera com instrumentos de comparação que vão além da estrutura de um órgão ou instituição. A avaliação externa leva em consideração a regulação, o controle e a hierarquização de órgãos ou instituições avaliadas. Nesta avaliação, a produção e os dados quantitativos são 
utilizados como critério para se estabelecer uma classificação qualitativa entre os entes avaliados (VERHINE; FREITAS, 2012; MACCARI; NISHIMURA, 2014). Porém, qualquer das duas modalidades de avaliação não pode ser concebida como finita. Qualquer avaliação requer reflexão contínua sobre o seu resultado. Esse processo dinâmico Dias Sobrinho (1998) denomina reavaliação ou meta-avaliação, que seria a avaliação da própria avaliação. Havendo necessidade, os instrumentos utilizados em uma avaliação podem ser corrigidos e aperfeiçoados. O importante é que a avaliação reflita sempre uma realidade mais próxima possível para que eventuais desajustes e inconsistências sejam corrigidos em um tempo futuro também breve.

Para Maccari e Nishimura (2014), na área educacional brasileira, inicialmente se utilizou o modelo interno de avaliações o qual tinha por meta identificar possíveis problemas e desajustes em órgãos e instituições. A utilização de avaliações externas como instrumento direcionado para a elaboração de políticas públicas na esfera do ensino, pesquisa ou extensão é algo mais recente. Por exemplo, o modelo de avaliação externa aplicado aos programas de pós-graduação stricto sensu brasileiros "tem sido reconhecido como um dos mais modernos e eficientes do mundo".

A criação da Coordenação de Aperfeiçoamento de Pessoal de Nível Superior - CAPES, nos anos de 1950, exemplifica esse novo olhar para as avaliações, as quais passaram a ser aplicadas como instrumentos importantes para o desenvolvimento científico e tecnológico brasileiros. A sua institucionalização, enquanto órgão responsável para estimular criação de programas de pós-graduação em áreas estratégicas, se mostrava vital para os novos desafios que o desenvolvimento econômico do país necessitava frente aos mercados interno e externo. A CAPES surgiu, conforme o Decreto $\mathrm{n}^{\circ} 29.741 / 1951$, com o propósito de assegurar a formação de "pessoal especializado em quantidade e qualidade suficiente para atender às necessidades dos empreendimentos públicos e privados" que visassem "o desenvolvimento econômico e social do país". Porém, será a partir dos anos de 1990 que a CAPES passa a se configurar como a principal agência de fomento no sistema nacional de Pós-Graduação. No ano de 1992, a CAPES foi transformada em fundação pública e passou a ter a função de subsidiar o Ministério da Educação na formulação de políticas públicas para todo o setor da pós-graduação brasileira. Coube à CAPES também a competência de articular a criação de novos cursos de mestrado e doutorado em todo o país. Para cumprir com esse objetivo, a CAPES passou a contar com recursos públicos para a concessão de bolsas de estudo, a publicação de editais visando à consolidação de núcleos de pesquisa, o estímulo de publicações qualificadas e outros instrumentos voltados para o fortalecimento da pesquisa e a capacitação de recursos humanos qualificados para o ensino superior.

Visando cumprir à sua missão de expansão e consolidação da pós-graduação brasileira, a CAPES, ao longo das três últimas décadas, tem se empenhado em construir e desenvolver um sistema de avaliação sustentando por indicadores que consigam representar quantitativamente a realidade da pesquisa no país. Nesse período, o sistema já passou por aperfeiçoamentos significativos sempre com o propósito de expressar de forma fidedigna a realidade de cada programa, de cada área e do sistema de pós-graduação no seu todo. Evidentemente que sempre buscando garantir as especificidades qualitativas de cada área de conhecimento avaliada.

O sucesso da CAPES, enquanto órgão estimulador da pós-graduação brasileira, fica evidente na medida em que se constata um crescimento expressivo em termos de qualidade e quantidade de programas de mestrados e doutorados em todas as áreas do conhecimento nos últimos anos. Maccari (2008) destaca que desde a implantação do sistema de avaliação, no ano de 1976, a CAPES vem cumprindo com êxito a sua missão relevante para o desenvolvimento qualitativo dos programas de pós-graduação e o fortalecimento da pesquisa científica e tecnológica do país. 


\section{A INSTITUCIONALIZAÇÃO DA CAPES ENQUANTO ÓRGÃO DE FOMENTO E DE CONTROLE}

A CAPES possui suas origens no Decreto no 29.741, de 11 de julho de 1951. Esse Decreto foi o responsável pela instituição de uma comissão responsável em promover uma Campanha Nacional de Aperfeiçoamento de Pessoal de Nível Superior. Essa comissão, sob a Presidência do Ministro da Educação e da Saúde, contou com representantes das seguintes instituições públicas e privadas: Departamento Administrativo do Serviço Público, Fundação Getúlio Vargas, Banco do Brasil, Comissão Nacional de Assistência Técnica, Comissão Mista Brasil-Estados Unidos, Conselho Nacional de Pesquisas, Instituto Brasileiro de Geografia e Estatística, Confederação Nacional da Indústria, Confederação Nacional do Comércio (art $1^{\circ}$, do Decreto $\mathrm{n}^{\circ}$ 29.741/1951).

De acordo com o Decreto n ${ }^{\circ} 29.741 / 1951$, referida Campanha possuía dois objetivos fundamentais. O primeiro objetivo seria o de "assegurar a existência de pessoal especializado em quantidade e qualidade suficiente para atender às necessidades dos empreendimentos públicos e privados" que visassem "o desenvolvimento econômico e social do país" (alínea "a", art. 2"); e, o segundo objetivo era o de "oferecer aos indivíduos mais capazes, sem recursos próprios, acesso a todas as oportunidades de aperfeiçoamento" (alínea "b", art. $2^{\circ}$ ).

Para que os objetivos fossem cumpridos, a comissão deveria realizar estudos das reais necessidades do "país em matéria de pessoal especializado", principalmente "nos setores onde se verificasse escassez de pessoal em número e qualidade" (alínea "a", art. 3); como também o de "promover a instalação e expansão de centros de aperfeiçoamento e estudos de pós-graduados" (alínea "f", art. $3^{\circ}$ ).

Conforme destaca Gouvêa (2012, p. 8) a composição da comissão dos representantes da CAPES refletia a "política desenvolvimentista" e o "consequente modelo de industrialização implantado no País", o qual procurava reforçar e dar ênfase na "relação entre economia e educação, evidenciando a necessidade da formação de quadros de nível superior para suprir as lacunas determinadas por um novo ritmo de crescimento econômico".

Coube, no entanto, ao Decreto $n^{\circ} 50.737$, de 7 de junho de 1961, estabelecer a forma e a organização da Companha Nacional de Aperfeiçoamento de Pessoal de Nível Superior. O novo Decreto passou a não utilizar mais a expressão "Campanha", conforme previa o Decreto $\mathrm{n}^{\circ}$ 29.741/1951. Pelo novo Decreto de 1961, a Companha passaria a ter um Conselho Consultivo (art. $3^{\circ}$ ), integrado por onze membros, todos de livre nomeação do Presidente da República, inclusive o seu coordenador. Além de outros membros, passariam a ter direito a um representante junto ao Conselho Consultivo da Companha as seguintes instituições públicas e privadas: a Presidência da República, o Ministério da Educação e Cultura, o Ministério do Trabalho e Previdência Social, o Ministério das Relações Exteriores, o Conselho Nacional de Pesquisas, o Banco Nacional do Desenvolvimento Econômico, a Confederação Nacional da Indústria e a Confederação Nacional do Comércio (art. $4^{\circ}$ ).

Pelo Decreto n ${ }^{\circ} 50.373 / 1961$, a Companha passaria a trabalhar com o meta mais clara e definida que seria a de estimular a "melhoria das condições de ensino e pesquisas dos centros universitários brasileiros, visando a uma melhor formação dos quadros profissionais de nível superior do país" (inciso 1 , art. $2^{\circ}$ ). As demais metas estariam voltadas para "o aperfeiçoamento do pessoal de nível superior já existente, promovido em função das prioridades ditadas pelas necessidades do desenvolvimento econômico e social do País" (inciso 2, art. 20); para "a realização de levantamentos, estudos e pesquisas sobre os problemas envolvidos em seu campo de ação"(inciso 3, art. $2^{\circ}$ ); e, por fim, para "a administração das bolsas de estudo oferecidas pelo Governo Brasileiro a latino-americanos e afro-asiáticos para cursos de graduação e pósgraduação no Brasil" (inciso 4, art. $2^{\circ}$ ). 
Com o Decreto $\mathrm{n}^{\circ}$ 53.932, de 26 de maio de 1964, foi redefinida a estrutura da CAPES e substituída a palavra "Companha" pela expressão "Coordenação". Outra mudança significativa trazida pelo Decreto foi à subordinação da Coordenação do Aperfeiçoamento de Pessoal de Nível Superior (CAPES) diretamente ao Ministério da Educação e Cultura. O Decreto manteve as diretrizes gerais de atuação previstas pela legislação anterior.

Será com o Parecer n ${ }^{\circ}$ 977/65, elaborado por Newton Sucupira, membro do Conselho Federal de Educação, em resposta a manifestação do Ministro da Educação, que a estruturação do sistema nacional de pós-graduação brasileiro finalmente vai ser parametrizada. O referido parecer aprovado pela Comissão de Educação Superior do então Conselho Federal de Educação definirá e regulamentará os parâmetros de funcionamento da atual pós-graduação stricto e lato sensu brasileira (SANTANA; MARTINS, 2012).

A partir do ano de 1976, é que a CAPES começou a coletar informações dos cursos de pós-graduação como forma de estabelecer parâmetros para a concessão de bolsa de estudos. As coletas passaram a ser realizadas anualmente a partir de dados sobre alunos matriculados, titulados e vagas ofertadas. De forma gradual, o sistema de coleta passou a incorporar dados referentes aos docentes, discente, disciplinas, produção científica e projetos de pesquisa. A partir de 1978, a CAPES implantou o sistema de avaliação por representações das áreas de conhecimento. As comissões passaram a ser compostas por renomados pesquisadores de cada área. O principal objetivo da avaliação ainda se voltava para a concessão de bolsas de estudos (SANTANA; MARTINS, 2012).

As mudanças significativas das avaliações voltadas para a qualidade dos cursos de pósgraduação vão ocorrer a partir dos anos de 1980 com a publicação do Decreto no 86.791, quando a CAPES passa a ser reconhecida como o órgão responsável pela elaboração do Plano Nacional de Pós-Graduação stricto sensu. O mesmo decreto também reconhece a CAPES como a Agência Executiva do Ministério da Educação e Cultura, junto ao sistema nacional de Ciência e Tecnologia, responsável pela elaboração, avaliação, acompanhamento e coordenação das atividades relativas ao ensino superior. Foi, portanto, a partir desse contexto que os resultados das avaliações passaram a ser publicizados e os parâmetros de qualidade entre os programas de pósgraduação das diferentes áreas de conhecimento passaram a ficar mais transparentes.

A partir do ano de 1998, o sistema de avaliação se tornou mais consistente e objetivo com o aperfeiçoamento da "padronização de notas, critérios de qualidade de produção científica e de formação de alunos, considerados fatores primordiais a melhoria do desempenho dos cursos, em substituição dos conceitos adotados até então". Desse ano em diante a Diretoria de Avaliação da CAPES passou a contar nos processos de avaliações com a colaboração da comunidade acadêmica e científica por meio de consultores ad hoc (MACCARI, 2008).

Maccari (2008) destaca que com a introdução de novas tecnologias de informação, ocorrida no final da década de 1990, houve significativas conquistas para o sistema de avaliação. Principalmente na divisão entre as áreas de conhecimento e, fundamentalmente, na implantação de quesitos rígidos para atribuição de notas para cada curso de pós-graduação. Todos os quesitos (1) Proposta do Programa; (2) Corpo Docente; (3) Corpo Discente; (4) Produção Intelectual; (5) Impacto Social e seus itens de avaliação alcançam um grau máximo de objetividade e são aplicados indistintamente para todas as áreas de conhecimento, ou seja, o sistema é monolítico e padronizado. Podendo haver tão somente pesos de quesitos e dos itens diferenciados de acordo com a realidade e caraterísticas de cada área de conhecimento. Destaca-se que essa diferenciação de pesos dos quesitos e itens é de responsabilidade das próprias áreas de conhecimento.

A Portaria $n^{\mathbf{o}}$ 99, de 21 de dezembro de 2005, instituiu a coleta de dados, anual e eletrônica, de todos os diplomas de mestres e doutores outorgados por instituição estrangeira e reconhecidos por instituições brasileiras. Essa exigência desde que foi instituída contribuiu sensivelmente para o estabelecimento de parâmetros de qualidade entre os programas de pósgraduação brasileiros. Conforme destaca Maccari (2008) “desde a sua criação a CAPES tem sido 
o principal instrumento para que o sistema de pós-graduação brasileiro funcione de forma integrada, planejada e consistente em busca do desenvolvimento tecnológico e científico". Atualmente, as atividades da CAPES estão definidas por linhas de ação e cada qual estruturada por programas específicos. Para o presente estudo, dentre as várias linhas de ação da CAPES, destaca-se o compromisso institucional com a avaliação da pós-graduação stricto sensu, bem como com o acesso e divulgação da produção científica dos programas de pós-graduação de forma transparente.

Para atender o compromisso com a qualidade das avaliações dos programas de pósgraduação, a CAPES vem constantemente aperfeiçoando o seu sistema de coleta de dados, possibilitando o cruzamento e a quantificação dos dados fornecidos pelos programas de pósgraduação por meio da plataforma Sucupira. O principal objetivo do aperfeiçoamento do sistema de avaliação, conforme destaca Maccari (2008), é o de retratar "de forma mais fiel [possível] a realidade do sistema de pós-graduação brasileiro". Por meio do sítio da CAPES (https://sucupira.capes.gov.br/sucupira/) é possível acessar qualquer informação dos programas de pós-graduação credenciados. O sistema pode ser alimentando com as informações do ano base a qualquer momento pelos programas de pós-graduação. Havendo inconsistências de dados, o próprio sistema alerta para que as correções sejam efetuadas. O acesso livre do sistema permite a garantia da transparência do sistema de avaliação e, principalmente, que os programas tenham entre si parâmetros comparativos de metas e qualidade.

Conforme a página da CAPES (http://www.capes.gov.br) (link avaliação) são apresentadas as quarenta e oito áreas de conhecimento. Para facilitar o processo de avaliação, as áreas são divididas, por critérios de afinidades, em dois níveis. O primeiro nível é formado por três colégios e o segundo nível é formado por nove grandes áreas. A área do Direito está incluída no Colégio Humanidades que, por sua vez, engloba a Grande área de Ciências Sociais Aplicadas. O Colégio de Humanidades é composto por três grandes áreas: a) a área de ciências humanas, b) a área de ciências sócias aplicadas; e, c) a área de linguística, letras e artes.

A plataforma Sucupira disponibiliza o relatório anual de todos os programas que fazem parte das quarenta e oito áreas de conhecimento. Ainda na página da CAPES, no link avaliação, todas as fichas das avaliações trienais dos programas estão disponíveis para consulta. Pelo sistema disponibilizado pela CAPES, é possível verificar sobre o tempo médio de titulação de mestres e doutores, sobre a quantidade de orientações de cada docente que compõe o corpo permanente dos programas, a quantidade de entrada e de titulação no ano base, as disciplinas ministradas na graduação e no programa por docente, a vinculação em projetos de pesquisas, além de outras informações quantitativas que podem apresentar diagnósticos favoráveis ou não à consolidação do programa. Todo processo de avaliação do sistema nacional de pós-graduação, conforme foi estruturado a partir do ano de 1988, é acompanhado pela Diretoria de Avaliação da CAPES.

A comunidade acadêmico-científica participa diretamente por meio de consultores $\mathrm{ad}$ hoc. Com as avaliações periódicas, a CAPES certifica a qualidade da pós-graduação brasileira. Essa certificação é utilizada como principal referência para a distribuição de bolsas e de recursos para o fomento à pesquisa. A avaliação também é utilizada como instrumento importante para a identificação de possíveis assimetrias regionais e orientação de ações de indução na criação e expansão de áreas estratégicas para o sistema nacional de pós-graduação. O sistema de avaliação da pós-graduação brasileiro é dividido em dois momentos distintos. O primeiro momento é de entrada no sistema nacional de pós-graduação e o segundo é o de sua permanência. A entrada no sistema ocorre por meio da avaliação das propostas de cursos novos (APCNs) e a permanência ocorre por meio da avaliação periódica dos cursos de pós-graduação, por meio das informações prestadas pelos programas no Sistema Sucupira. Nos dois momentos, os procedimentos adotados nas avaliações devem ter por base: a) confiabilidade e reconhecimento na qualidade nos pareceres emitidos pelos pares; b) atualização dos critérios pela comunidade acadêmico-científica advindos 
dos debates a cada período a ser avaliado; e, c) divulgação das decisões, das ações e dos resultados de forma pública e transparente no sítio da CAPES e nas páginas de cada área de conhecimento.

No processo de elaboração, submissão ou avaliação de cursos novos ou de permanência dos programas os documentos de cada área representam a principal referência para os novos projetos. Nos documentos de área devem estar descritos momento atual, as características e as especificidades da área e as perspectivas de desenvolvimento. Nos documentos de área ainda devem constar os quesitos considerados prioritários para o processo de avaliação dessa área de conhecimento. Juntamente com as "fichas de avaliação e os relatórios de avaliação, os documentos de área constituem o trinômio que expressa os processos de avaliação e os resultados" (CAPES, 2016a) das avaliações periódicas.

A relevante importância da CAPES no processo de formação de mestres e doutores em todas as áreas de conhecimento induzidas pela eficiência do sistema nacional de avaliação, é indiscutível. A evolução de bolsas ativas no exterior entre os anos de 2011 a 2014 é significativa. Naturalmente que o crescimento gradativo na concessão de bolsas no país e no exterior vem acompanhado pela eficiência indutiva do sistema de avaliação dos programas de pós-graduação. A partir da qualidade dos programas é possível identificar áreas estratégicas e áreas que necessitam de estímulos, daí o estímulo à capacitação de pesquisadores é fundamental.

A partir dos dados e das informações relatados acima, pode-se concluir que a CAPES ocupa lugar de destaque junto ao processo de desenvolvimento, crescimento e fortalecimento do sistema de Pós-graduação brasileiro. Por sua vez, a construção do sistema nacional de avaliação dos programas de Pós-graduação que leve em consideração a transparência e elementos quantitativos se apresenta como o maior desafio para todo sistema. A atribuição de qualidade sobre pesquisas e publicações deve ser de responsabilidade de cada área de conhecimento. A análise de qualidade deve ser traduzida e contextualizada em dados quantitativos, daí a necessidade de um sistema de avaliação que consiga traduzir a realidade de cada programa de Pós-graduação dentro da sua própria área de conhecimento. Tanto a análise dos dados de qualidade como a de quantidade deve possuir critérios claros e objetivos, caso contrário compromete-se toda a seriedade e consistência do processo de avaliação.

Considerando, portanto, a relevância da CAPES enquanto órgão de fomento, de regulação e de coordenação do sistema nacional de avaliação, faz-se necessário analisar qual o impacto e como os programas de pós-graduação incorporam em sua lógica e dinâmica os critérios a quem são submetidos pelas avaliações. A partir da identificação desses procedimentos internos o que se pretende é desenhar estratégias que a médio e longo prazos possam contribuir para o desenvolvimento dos programas de pós-graduação. Para atender o objetivo do presente estudo, serão analisados os dados consolidados pelas duas últimas avaliações trienais a de 2010 e a de 2013, limitados à área do Direito. A investigação levará em conta somente a análise dos dados quantitativos das avaliações com o quais se pretende alinhavar as melhores estratégias e procedimentos para o fortalecimento e consolidação de critérios qualitativos para toda a área do Direito.

A realização de pesquisas com esse enfoque se justifica na medida em que a própria CAPES por meio do Plano Nacional de Pós-graduação (PNPG 2011-2020) destaca que os resultados das avaliações devem servir de base para a formulação de políticas públicas estratégicas para o desenvolvimento e fortalecimento do sistema de pós-graduação brasileiro com ações de fomento em bolsas de estudos, custeio, auxílios, cooperações, acordos e de criação de novos cursos de mestrados e doutorados. A tabela a seguir ilustra a evolução da área do direito nas trienais de 2010 e 2013: 
Tabela 1 - Programas e conceitos da área de Direito nos triênios 2010 e 2013

\begin{tabular}{|c|r|r|}
\hline Conceito & $\begin{array}{l}\text { Programas da } \\
\text { área Trienal } \\
\text { (2010) }\end{array}$ & $\begin{array}{l}\text { Programas da } \\
\text { área } \\
\text { Trienal }(\mathbf{2 0 1 3})\end{array}$ \\
\hline $\mathbf{7}$ & $0(0 \%)$ & $0(0 \%)$ \\
\hline $\mathbf{6}$ & $6(9,23 \%)$ & $8(10,66 \%)$ \\
\hline $\mathbf{5}$ & $14(21,53 \%)$ & $10(13,33 \%)$ \\
\hline $\mathbf{4}$ & $12(18,46 \%)$ & $26(34,66 \%)$ \\
\hline $\mathbf{3}$ & $27(41,53 \%)$ & $30(40,00 \%)$ \\
\hline $\mathbf{2}$ & $4(6,15 \%)$ & $1(1,33 \%)$ \\
\hline Total & $63(100 \%)$ & $75(100 \%) \square$ \\
\hline
\end{tabular}

$\mathrm{Na}$ avaliação trienal de 2010 dos sessenta e três programas avaliados, quarenta foram programas que possuíam apenas o curso de Mestrado e os vinte e três restantes foram compostos por programas que possuíam cursos de Mestrado e Doutorado (CAPES, 2010). Na trienal de 2013, a área do Direito aumentou para setenta e cinco programas avaliados. Destes, quarenta e cinco possuíam somente o curso de Mestrado e trinta programas possuíam os cursos de Mestrado e Doutorado (CAPES, 2014).

Quando se analisa os dados da tabela 1, sobre o desempenho do curso de Direito da trienal de 2010 em relação à trienal de 2013, percebe-se que houve uma diminuição do número de programas que foram descredenciados passando de 4 para 1. Isso indica que a área do Direito está mais atenta aos critérios mínimos de qualidade exigida pelo sistema de avaliação. Agora, um dado que causou estranheza foi a diminuição numérica e percentualmente dos programas no estrado 5, haja vista a notável evolução que a área teve em relação às produções mais qualificadas na trienal de 2013. Segundo estudo de Maccari e Nishimura (2014, p. 615), a área de Direito produziu duzentos e dois artigos A1, quatrocentos e dezoito artigos A2 e obteve um acréscimo de quinze por cento na titulação de doutores, sendo que o número saltou de setecentos e cinquenta e oito titulados na trienal de 2010, para oitocentos e setenta e um na trienal de 2013.

De acordo com CAPES (2016), a área de Direito em junho de 2016 contava com noventa e sete programas; destes, sessenta programas possuíam apenas curso de Mestrado, quatro programas com cursos de mestrado profissional e trinta e três programas com cursos de Mestrado e Doutorado. A distribuição dos programas nos estratos foi a seguinte: a) nenhum programa (0\%) com o conceito 7 ; b) oito programas $(8,24 \%)$ com o conceito 6 ; c) dez programas $(10,30 \%)$ com o conceito 5 ; d) vinte e seis programas $(26,80 \%)$ com o conceito 4 ; e, cinquenta e quatro programas $(54,63 \%)$ com o conceito 3 (CAPES, 2016a).

A partir desses dados, pode-se concluir que a área do Direito está em plena acessão em termos de crescimento numérico com o reconhecimento de novos programas de mestrados e doutorados; daí, a necessidade urgente de se conhecer, discutir e construir uma métrica de avaliação que seja transparente, contínua, consistente e, fundamentalmente, republicana, capaz de garantir que o sistema de avaliação reflita de forma concreta a realidade de cada programa de pós-graduação e, por fim, da área de Direito como um todo. Só a partir da construção de requisitos e critérios claros e maduros, construído por toda a área do Direito, será possível garantir que cada programa de pós-graduação estabeleça estratégias de gestão e de crescimento dentro da área. As regras previamente aprovadas por toda a área devem ser contínuas e, havendo a necessidade de revisões, as mesmas devem ser discutidas de forma ampla e transparentes; caso 
contrário, a estratégia estabelecida pelos Programas de Pós-Graduação dentro do período de avaliação perde completamente o sentido.

\section{OS INSTRUMENTOS APLICADOS NO SISTEMA DE AVALIAÇÃO DA CAPES}

A partir de 2014, a CAPES passa a operar com o sistema de coleta de dados chamado de Plataforma Sucupira. A escolha do nome da Plataforma é uma homenagem ao Professor Newton Sucupira, autor do Parecer no 977/1965, conhecido como Parecer Sucupira, responsável pela formatação e institucionalização do sistema de pós-graduação que até hoje se mantém no país. A nova ferramenta foi desenvolvida como o propósito de coletar informações, proporcionar a análise e o cruzamento de dados. A Plataforma foi construída para se tornar a base de referência do Sistema Nacional de Pós-Graduação (SNPG). Todas as informações, processos e procedimentos realizados pela CAPES estão disponibilizadas em tempo real e com muito mais transparência, se for considerado o sistema de coleta anterior. A nova Plataforma possibilita que toda a parte gerencial-operacional dos processos seja alimentada e administrada pelos pró-reitores e coordenadores dos programas de pós-graduação cadastrados. Essa nova sistemática de coleta e apresentação dos dados da pós-graduação brasileira vem ratificar um dos pilares do sistema de avaliação que é assegurar a comparabilidade entre programas e áreas que compõe todo o sistema.

A expectativa é de que a Plataforma Sucupira possibilite para os processos seguintes os avanços que seguem: a) maior transparência dos dados para toda a comunidade acadêmica; b) redução do tempo, esforços e imprecisões na execução de avaliação do (SNPG; c) maior facilidade no acompanhamento da avaliação; d) maior confiabilidade, precisão e segurança das informações; e, e) controle gerencial mais eficiente (CAPES, 2015).

Para a CAPES, a grande contribuição para as instituições de ensino e para os programas de pós-graduação, com a nova Plataforma, será: a) maior facilidade e simplicidade no processo de coleta/envio das informações; b) imediata visibilidade das informações da instituição; c) maior agilidade no processo de solicitação e facilidade na comunicação junto à CAPES; d) melhor acesso e maior disponibilidade de informações sobre o SNPG para elaborar metas, ações e políticas institucionais e respectivos planos de desenvolvimento; e) envio de informações continuamente em tempo real ao longo do ano; e, f) possibilidade de integração com sistemas de registro acadêmico-corporativo (CAPES, 2015).

O módulo de coleta de dados na Plataforma Sucupira apresenta uma estrutura com os mesmos campos de informações do sistema de coleta anterior. A mudança mais significativa da nova plataforma está na possibilidade de inserção de informações pelos programas de pósgraduação de forma contínua e online. Todos os dados dos programas, atividades e produção do corpo docente podem ser inseridos na plataforma a qualquer momento. O cadastro de entrada e saída de discentes pode ser realizado de forma instantânea na plataforma. A Plataforma permite a consolidação de cadastros de docentes, discentes e participantes externos pelo Cadastro Nacional de Pessoa Física (CPF).

Assim, com o cruzamento de dados com os demais programas de pós-graduação de todas as áreas é facilitado a identificação possíveis duplicações e inconsistências. A Plataforma possibilita a construção de uma base de dados de periódicos por meio da validação dos ISSN (número identificador do periódico). Por meio da interface com a plataforma Lattes do Conselho Nacional de Desenvolvimento Científico e Tecnológico (CNPq) cada programa de pós-graduação poderá importar os dados da produção intelectual de seus docentes, pesquisadores e discentes. A partir da inserção de novos dados os programas de pós-graduação poderão gerar relatórios consolidados e verificar possíveis inconsistências, bem como se o planejamento e metas anuais estão sendo cumpridas. A Plataforma também está integrada com o Sistema de Acompanhamento de Concessões (SAC) da CAPES. Desta forma, toda matrícula ou titulação de discentes inserida no sistema possibilitará o pagamento ou o cancelamento de bolsa de estudo, quando houver 
necessidade. Em síntese, a Plataforma Sucupira apresenta ferramentas e aplicativos que permitem a coleta de dados, a gestão do SNPG, à submissão e análise de projetos de cursos novos, apresentação de proposta de mestrados e doutorados interinstitucionais (Minter e Dinter), o cruzamento de dados sobre periódicos (Qualis), as fichas de avaliações (quadrienais), acompanhamento anual, reuniões e visitas. As ferramentas e aplicativos que ainda não estão operando serão gradativamente incorporados à plataforma.

O principal instrumento utilizado nas avaliações realizadas pela CAPES é a ficha de avaliação. Cabe destacar que partir de 2013 passou a vigorar a avaliação quadrienal; antes, as avaliações eram trienais. Nas avaliações são atribuídos conceitos aos programas que segue a escala de 1 (um) a 7 (sete), que é consolidado pela ficha de avaliação. O programa que conseguir conceito superior a nota 3, permanecerá fazendo parte do SNPG e o diploma por ele expedido valerá para todo o Brasil. Já os programas que obtiverem notas 1 ou 2 serão descredenciados. A CAPES permite, dentro de um prazo pré-estabelecido, que os programas entrem com recursos para alteração da nota recebida. Este recurso é analisado novamente pelo Comitê de Área e, posteriormente, será homologado pelo Conselho Técnico Científico (CTC). Os programas que receberem notas inferior a 3 e não conseguirem elevar esta nota após o recurso, não podiam abrir novas turmas até que os apontamentos realizados na ficha de avaliação pelo Comitê da Área seja cumprido. Isto poderá ocorrer por meio de uma nova entrada do curso no APCN.

O programa de pós-graduação só fará parte do sistema nacional quando o seu conceito for igual ou maior a 3. O conceito 1 é atribuído ao programa deficiente, o conceito 2 é atribuído ao programa fraco, o conceito 3 é atribuído ao programa regular que atende os requisitos mínimos de qualidade para o credenciamento, o conceito 4 é atribuído ao programa bom, o conceito 5 é atribuído ao programa muito bom, sendo reconhecido que o programa é de excelência nacional. Os conceitos 6 e 7 são atribuídos para os programas que apresentarem indicadores de destaque na internacionalização. A progressão para o conceito 6 e 7 somente pode contemplar o programa que obteve o conceito 5 na avaliação. Caso o programa possua desempenho equivalente ao de centros de pesquisas internacionais de excelência da respectiva área e desempenho altamente diferenciando na inserção internacional em relação aos demais programas que obtiveram o conceito 5 na área, poderá ser atribuído o conceito 6 ou 7, dependendo da consistência dos dados e de sua inserção internacional contínua e solidária.

A ficha de avaliação aplicada pela área do Direito tanto nas avaliações trienais de 2010 e de 2013 se constituía por cinco quesitos, sendo que cada quesito era formado por um número de itens a serem avaliados. Cada item foi avaliado individualmente entre os conceitos de muito bom (nota 5), bom (nota 4), regular (nota 3), fraco (nota 2) e deficiente (nota 1). Faz-se importante destacar que a distribuição quantitativa dos pesos entre os quesitos e itens é de responsabilidade de cada área de conhecimento. A ficha de avaliação apresenta os mesmos quesitos e itens para todas o que muda são os pesos. Assim, para a área do Direito apresentam-se os seguintes quesitos: 1 - Proposta do Programa, três itens; 2 - Corpo docente, quatro itens; 3 - Corpo discente, quatro itens; 4 - Produção Intelectual, três itens; 5 - Inserção Social, três itens.

De modo geral, os quesitos (Proposta do Programa e Impacto Social) são de característica qualitativa; os demais, são quantitativos. De acordo com Maccari et al (2009, p.6) "nota-se que $80 \%$ dos itens do sistema de avaliação são de caráter quantitativo; os $20 \%$ restantes são qualitativos, mas medidos em parte de forma quantitativa. Daí necessidade de se estabelecer critérios e procedimentos claros e objetivos na qualificação dos dados por toda a área de conhecimento". Nesse sentido, Maccari et al (2009) destaca que o resultado final do sistema de avaliação aplicado pela CAPES acaba levando em consideração apenas critérios quantitativos dos dados coletados e sistematizados de cada Programa de Pós-graduação. Daí a necessidade de se construir critérios claros e objetivos pelas áreas de conhecimento no que diz respeito a avaliação qualitativa que antecede a avaliação quantitativa. 
Em termos de peso entre os cinco quesitos da ficha de avaliação pode-se destacar que a qualidade da avaliação está praticamente sustentada nos aspectos que envolvem o corpo docente permanente de cada Programa de Pós-Graduação, isto pelo fato de que quase todos os demais quesitos dependem fundamentalmente dos índices de produção e atuação dos docentes junto ao programa e à instituição de ensino. Na ficha de avaliação, a formação, atuação e produção intelectual do corpo docente permanente se refletem diretamente em dois requisitos que juntos representam sessenta por cento de toda avaliação (corpo docente $20 \%$ e produção intelectual $40 \%$ ). Os outros quarenta por cento (quesito corpo discente, teses e dissertações - 30\% e quesito inserção social - 10\%) da ficha de avaliação depende exclusivamente da atuação direta do corpo docente permanente no processo de orientação de teses, dissertações e produções científicas do corpo discente, bem como da inserção e impacto social, local, regional, nacional ou internacional do Programa de Pós-Graduação.

O quesito da ficha de avaliação denominado de "proposta do programa" não possui peso; no entanto, o não cumprimento de seus itens é determinante para a aprovação de qualquer proposta de Programa de Pós-Graduação. Após a autorização para o funcionamento de Programa de Pós-Graduação, esse quesito passa a ser avaliado normalmente podendo, se necessário, haver diligências, visitas ou até mesmo o descredenciamento do programa caso a avaliação do quesito não se enquadre como regular (nota 3), bom (nota 4) ou muito bom (nota 5). Nesse quesito são avaliados os seguintes itens: 1.1 - coerência, consistência, abrangência e atualização das áreas de concentração, linhas de pesquisa, projetos em andamento e proposta curricular (peso no quesito de 50\%); 1.2 - planejamento do programa com vistas a seu desenvolvimento futuro, contemplando os desafios internacionais da área na produção do conhecimento, seus propósitos na melhor formação de seus alunos, suas metas quanto à inserção social mais rica dos seus egressos, conforme os parâmetros da área (peso no quesito de 20\%); 1.3 - infraestrutura para ensino, pesquisa e, se for o caso, extensão (peso no quesito de 30\%). Destaca-se que as informações contidas no critério (1) Proposta do Programa servem de base e complementam a avaliação do critério (5) Inserção Social do Programa.

O quesito do "corpo docente permanente", com peso de $20 \%$, previsto na ficha de avaliação, está composto pelos seguintes itens: 2.1 - Perfil do corpo docente, consideradas titulação, diversificação na origem de formação, aprimoramento e experiência, e sua compatibilidade e adequação à proposta do programa (25\%); 2.2 - Adequação e dedicação dos docentes permanentes em relação às atividades de pesquisa e de formação do programa (30\%); 2.3 - Distribuição das atividades de pesquisa e de formação entre os docentes do programa (30\%); 2.4 - Contribuição dos docentes para atividades de ensino e/ou de pesquisa na graduação, com atenção tanto à repercussão que este item pode ter na formação de futuros ingressantes na pós-graduação, quanto na formação de profissionais mais capacitados no plano da graduação $(15 \%)$.

O quesito da "produção intelectual", com peso de 40\%, está composto pelos seguintes itens: 3.1 - publicações qualificadas do programa por docente permanente $(40 \%) ; 3.2$ distribuição de publicações qualificadas em relação ao corpo docente permanente do programa (30\%); 3.3 - produção técnica, patentes e outras produções consideradas relevantes (30\%). Fazse importante destacar que a atuação do corpo docente permanente no Programa de PósGraduação se reflete em dois outros quesitos da avaliação: no quesito "corpo discente, teses e dissertações" e no quesito "inserção social do programa".

A produção intelectual qualificada dos docentes permanentes do Programa de PósGraduação está formada pela estratificação de dados, na qual se verifica a qualidade da produção publicada em periódicos. Na análise das publicações, é levada em consideração a enxogenia (de artigos e avaliadores), periodicidade, fator de impacto e aplicação da avaliação duble blind review ou avaliação dupla cega. A avaliação dupla cega deve ser feita por pares, aonde cada artigo é avaliado por dois especialistas na área, sem a identificação de autoria e dos avaliadores. 
Para todos os efeitos, a estratificação dos periódicos deve ser realizada todo ano pelas áreas de conhecimento por meio da análise dos relatórios internos de cada periódico. Os estratos dos periódicos seguem a seguinte ordem: A1 (estrato mais alto e de maior pontuação), A2, B1, B2, B3, B4, B5 e C, estrato sem peso. A produção no estrato C não é considerada para efeitos qualitativos; portanto, não gera impacto para a avaliação quantitativa dos docentes permanentes. Cada estrato, menos o estrato $\mathrm{C}$, terá um peso e no fechamento da avalição é gerada a média de publicações qualificadas de cada docente permanente por programa e por docente. Com o resultado, será gerada a classificação para os indicadores do item, podendo ser muito bom (nota 5), bom (nota 4), regular (nota 3), fraco (nota 2) ou deficiente (nota 1).

O quesito "corpo discente, teses e dissertações", possui peso de $30 \%$, e é composto pelos seguintes itens: 4.1 - quantidade de teses e dissertações defendidas no período de avaliação, em relação ao corpo docente permanente e à dimensão do corpo discente (30\%); 4.2 - distribuição das orientações das teses e dissertações defendidas no período de avaliação em relação aos docentes do programa (20\%); 4.3 - qualidade das teses e dissertações e da produção de discentes autores da pós-graduação e da qualidade na produção científica do programa, aferida por publicações e outros indicadores pertinentes à área (30\%); 4.4 - eficiência do programa na formação de mestres e doutores bolsistas: tempo de formação de mestres e doutores e percentual de bolsistas titulados $(20 \%)$.

O quesito "inserção social" do Programa de Pós-Graduação decorre diretamente da qualidade de projeção acadêmica local (nota 3), regional (nota 4), nacional (nota 5) e internacional (nota 6 ou 7) de seu corpo docente permanente e das informações provenientes da Proposta do Programa. Este critério possui peso total de 10\%, e é composto pelos seguintes itens: 5.1 - inserção e impacto regional e (ou) nacional do programa (40\%); 5.2 - integração e cooperação com outros programas e centros de pesquisa e desenvolvimento profissional relacionados à área de conhecimento do programa, com vistas ao desenvolvimento da pesquisa e pós-graduação (30\%); 5.3 - visibilidade ou transparência dada pelo programa à sua atuação $(30 \%)$.

Importante destacar que "o modelo de avaliação proposto pela CAPES" é apenas uma referência para que cada área de conhecimento possa adaptar conforme as suas especificidades. Cada área de conhecimento pode alterar até cinco por cento o peso dos quesitos para mais ou para menos. No que diz respeito aos itens que compõe cada quesito cada área de conhecimento "possuem maior flexibilidade para atribuírem pesos percentuais que julgarem ser mais adequado às suas características". A área de conhecimento também pode optar por não atribuir peso a determinados itens, com isso eles não serão levados em consideração na avaliação. Em regra, a flexibilização para que as áreas de conhecimento possam ajustar os quesitos e os itens de avaliação, conforme as suas características e realidade, busca principalmente garantir a "calibragem" e a equidade entre as áreas de conhecimento nas suas avaliações (MACCARI; NISCHIMURA, 2014, p. 607).

O que se destaca, porém, é que o núcleo principal de todo processo de avaliação está centrado na capacidade de articulação, produção e atuação do corpo docente do programa de pósgraduação. As publicações qualitativas e quantitativas, a atuação interna e externa do corpo docente permanente em projetos, disciplinas e orientações, a projeção local, nacional e internacional do corpo docente permanente, são itens determinantes para que o programa entre no sistema de pós-graduação e possa se manter e se consolidar como referência em sua área de conhecimento. 
A tabela que compõe os quesitos, itens e pesos da ficha de avaliação, aplicados pela a área do Direito nas avaliações trienais de 2010 e 2013, está estruturada da seguinte forma:

1 - Proposta do Programa

\section{Quesitos / Itens}

Peso

1.1. Coerência, consistência, abrangência e atualização das áreas de concentração, linhas de pesquisa, projetos em andamento e proposta curricular.

0\%

1.2. Planejamento do programa com vistas a seu desenvolvimento futuro, contemplando os desafios internacionais da área na produção do conhecimento, seus propósitos na melhor formação de seus alunos, suas metas quanto à inserção social mais rica dos seus egressos, conforme os parâmetros da área.

1.3. Infraestrutura para ensino, pesquisa e, se for o caso, extensão.

2-Corpo Docente

$50 \%$

2.1. Perfil do corpo docente, consideradas titulação, diversificação na origem de formação, aprimoramento e experiência, e sua compatibilidade e adequação à Proposta do Programa.

2.2. Adequação e dedicação dos docentes permanentes em relação às atividades de pesquisa e de formação do Programa.

2.3. Distribuição das atividades de pesquisa e de formação entre os docentes do Programa.

2.4. Contribuição dos docentes para atividades de ensino e/ou de pesquisa na graduação, com atenção tanto à repercussão que este item pode ter na formação de futuros ingressantes na PG, quanto (conforme a área) na formação de profissionais mais capacitados no plano da graduação.

\section{3 - Corpo Discente, Teses e Dissertações}

3.1. Quantidade de teses e dissertações defendidas no período de avaliação, em relação ao corpo docente permanente e à dimensão do corpo discente.

3.2. Distribuição das orientações das teses e dissertações defendidas no período de avaliação em relação aos docentes do programa.

3.3. Qualidade das Teses e Dissertações e da produção de discentes autores da Pós-Graduação e da graduação (no caso de IES com curso de graduação na área) na produção científica do programa, aferida por publicações e outros indicadores pertinentes à área.

3.4. Eficiência do Programa na formação de mestres e doutores bolsistas: Tempo de formação de mestres e doutores e percentual de bolsistas titulados.

4 - Produção Intelectual

4.1. Publicações qualificadas do Programa por docente permanente.

4.2. Distribuição de publicações qualificadas em relação ao corpo docente permanente do Programa.

4.3. Produção técnica, patentes e outras produções consideradas relevantes.

5 - Inserção Social

$20 \%$

$20 \%$

$25 \%$

$30 \%$

$30 \%$

$15 \%$

5.1. Inserção e impacto regional e (ou) nacional do programa.

5.2. Integração e cooperação com outros Programas e centros de pesquisa e desenvolvimento profissional relacionados à área de conhecimento do programa, com vistas ao desenvolvimento da pesquisa e da Pós-Graduação.

5.3 - Visibilidade ou transparência dada pelo programa à sua atuação. Fonte: CAPES 


\section{CRITÉRIOS E RESULTADOS DAS AVALIAÇÕES DE 2010 E 2013 APLICADOS NO QUESITO DE PRODUÇÃO INTELECTUAL}

Nesta parte do estudo serão apresentados os principais critérios e procedimentos adotados pela área do Direito na classificação e pontuação de periódicos, livros, capítulos de livros e coletâneas nas avaliações trienais de 2010 e 2013. Todos os dados, argumentos e justificativas foram retirados dos Documentos de Área publicados nos anos 2009 e 2013 e dos Relatórios de Avaliações publicados nos anos de 2010 e 2013, todo material está disponibilizado no sítio da CAPES (2016) por meio dos seus cadernos de indicadores.

\subsection{Classificação de Periódicos}

O relatório de avaliação da trienal de 2010 (CAPES, 2010b) informa que para o triênio 2007 a 2009 foi realizada "uma revisão profunda e rigorosa do Qualis de todos os periódicos nacionais e estrangeiros classificados no Sistema em 3 níveis". Os periódicos A1 e A2 foram reclassificados para B2. Os periódicos B1 foram reclassificados em B4 e os periódicos B2, B3, B4 forma reclassificados em B5.

O relatório informa que essa nova reclassificação foi adotada para os anos de 2007 e 2008. Para o ano de 2009, seguindo as recomendações da CAPES, a área do Direito adotou "critérios idênticos aos indexadores internacionais, com o indicativo da inclusão de todos os periódicos no scielo e em outros indexadores deste mesmo padrão". Dentro desse critério, para o ano de 2009, a área do Direito apenas considerou os periódicos com double blind review. Já na classificação desses periódicos se levou em consideração a "endogenia do Conselho Editorial, da autoria dos artigos e dos pareceristas ad hoc, auferidos por unidade da Federação".

O relatório ressalta que "a participação dos periódicos classificados nos estratos superiores de avaliação [representou] uma pequena percentagem, menos que $3 \%$ do total dos periódicos da área". Por sua vez, o "estrato B1 representou apenas 6\% do total, quase todos periódicos estrangeiros".

O relatório destaca que "a alteração na composição dos estratos foi muito significativa e observa-se um grande esforço de adaptação dos editores de periódicos e dos programas de pósgraduação, que deve render seus melhores frutos no próximo triênio [2010-2012]".

O relatório de 2010 (CAPES, 2010b) ainda informa que com a implantação dessa nova formula se "inverte a tradicional lógica de avaliação de publicações na Área do Direito". Pois, no passado se privilegiava "revistas dos próprios programas, marcadas por forte endogenia". Ainda, de acordo com o relatório, a área do Direito possuía no sistema Qualis "mais de 1400 periódicos registrados e todos pontuavam". Com a aplicação das exigências de "exogenia", da "dupla avaliação cega por pares" e da não pontuação "aos periódicos do estrato C, mais de 1000 periódicos ficaram sem pontuação e a Área passou a valorizar um número restrito de periódicos que atendem aos requisitos de indexação internacional”.

O impacto para toda área do Direito com a aplicação de novos critérios no último ano da trienal foi significativo, conforme o relatório de avaliação "menos de 10\% [dos periódicos ficaram] entre os estratos B1 e A2". Outro ponto que merece ser destacado é que os periódicos não tiveram o tempo para se adequar a estas exigências, o que certamente prejudicou a sua classificação.

Por esta mesma lógica de pensamento, por mais que os periódicos pudessem cumprir todas as exigências que foram solicitadas de última hora, poderia se chegar ao cúmulo agora de solicitar periódicos com Fator de Impacto em base de dados superior a x pontos. Ou seja, este tipo de forma de pontuar os periódicos causa mais danos à área do que necessariamente uma sinalização do que se pretende desenvolver ao longo dos próximos anos. 
O relatório reconhece que "os livros têm como principal veículo de informação da Área”. Essa constatação pode ser comprovada por meio do levantamento de dados realizado "pelos membros da Comissão [através do] Portal Domínio Público, a partir de 165 dissertações e teses de praticamente todos os programas do país", o Documento destaca "que os periódicos representam apenas $16 \%$ das fontes" citadas. Por sua vez, livros e capítulos de livros, representam $64 \%$ das fontes citadas.

O relatório de avaliação conclui que, na distribuição de pontos no resultado final da trienal de 2010, o peso maior dos livros é significantemente maior ao peso dos periódicos. Enquanto a soma de publicações em periódicos representou 88.670 pontos (27\%) do total, a soma dos livros, capítulos de livros e coletâneas representaram 242.488 pontos (64\%) do total. Por fim, o relatório conclui que com os novos critérios foi possível estabelecer "boa calibragem na distribuição de pontos" entre periódicos, livros, capítulos de livros e coletâneas.

Conforme relatam Varella e Roesler (2012, p. 693), ao final do período da trienal de 2010, "houve uma intervenção maior da Capes na área do Direito", segundo os autores registram "a Diretoria de avaliação: exigiu a aplicação de critérios de independência no julgamento dos artigos e maior exogenia dos periódicos para evitar distorções e aproximar a área de Direito das demais áreas do conhecimento; proibiu a classificação dos periódicos nacionais no estrato A, ao mesmo do primeiro ano; rebaixou todos os periódicos jurídicos em três níveis; e exigiu também a criação de um sistema de classificação dos livros".

Diante disso, segundo os autores, a área do Direito passou a trabalhar não mais com um "número mínimo de pontos para o programa ser bem avaliado. A avaliação final [passou a ser] subjetiva e realizada de forma comparada entre os programas". Aqui cabe um destaque que este tipo de orientação deveria ter sido dada para a área do Direito no início da trienal e não ao final. Assim, a área poderia ter avançado muito mais e, com a possibilidade de se levar em conta também as especificidades da área.

Para Varella e Roesler (2012, p. 694), a aplicação de novos critérios para a classificação de periódicos ao final da trienal de 2010 resultou em "alteração importante na classificação". Pois, "muitos periódicos antes bem classificados foram rebaixados e vice-versa. O perfil dos periódicos bem pontuados, provenientes de diferentes regiões do País, foi bastante alterado, privilegiando revistas de programas em consolidação", como, por exemplo, as revistas da "Univali, UEM, Unifor, FGV, UFC" as quais "atendiam aos requisitos dos indexadores internacionais há mais tempo".

Segundo os autores "com a intervenção [da CAPES na classificação dos periódicos na área do Direito], houve a redução global na avaliação dos periódicos. No entanto, ao mesmo tempo, houve maior distribuição dos pontos na área, pois as revistas bem pontuadas apenas o são porque publicam artigos de vários programas". A partir do argumento de que as revistas mais pontuadas publicam artigos dos programas em geral, os autores justificam que "todos os programas terão uma pontuação mais próxima à quantidade de artigos publicados, com um desvio padrão menos importante".

Para fundamentarem essa relação, os autores não apresentam qualquer dado mais sólido ou quantitativo. Esse argumento dos autores é muito limitado, deveriam ter colocado o número de artigos publicados nas revistas no triênio, a distribuição entre os programas, número de professores permanentes de cada programa e a nota. Com estes dados eles poderiam dizer que todos os programas tiveram uma pontuação mais próxima. E se um programa não teve esta pontuação o argumento ficaria sem consistência.

A relação entre causa e efeito é meramente empírica e subjetiva. Na prática, essa suposta "intervenção" da Diretoria da CAPES sobre a avaliação de periódicos foi inoportuna e não respeitou qualquer critério de transparência e de manutenção de regras existentes. Por outro lado, rebaixar periódicos tradicionais e elevar periódicos em consolidação de certa forma acaba 
prejudicando a pontuação de programas com conceitos maiores, favorecendo programas com conceitos mais baixos.

$\mathrm{Na}$ realidade a "intervenção" da Diretoria de avaliação da CAPES foi a de evitar a possiblidade de programas com o conceito 6 se habilitarem para o conceito 7. O controle de crescimento conceitual dos programas foi imposto de cima para baixo, com isso se inviabilizou a possiblidade de que a área do Direito nas avaliações trienais de 2010 e 2013 avançasse para o conceito 7. O ajuste conceitual entre os programas ficou limitado entre os conceitos mínimo 3 e máximo 6.

Para Varella e Roesler (2013, p. 695), a aplicação de novos critérios para avaliação dos periódicos na trienal de 2010 garantiu que o "resultado final da avaliação [proporcionasse] a melhor distribuição de pontos entre todos os programas do Brasil". Na contraposição desse argumento, pode-se afirmar que a qualidade de uma avaliação não está em se utilizar mecanismos compensem eventuais desequilíbrios no interior do sistema, está na capacidade do resultado da avaliação refletir a realidade individual e conjunta dos entes avaliados.

Na prática, o que se verifica é que houve melhor equilíbrio na distribuição de pontuação entre os programas; porém, esse equilíbrio foi gerado por mudanças de critérios de forma intempestiva. Na medida em que os periódicos nacionais classificados como "A" tiveram os seus estratos rebaixados e os periódicos "B" valorizados quem mais sofreu prejuízos com a pontuação foram os programas de pós-graduação com conceitos mais elevados.

Já o relatório de avaliação da trienal de 2013 (CAPES, 2013b) informa que, por meio da Comissão do Qualis-periódicos, foram realizadas três reclassificações de periódicos no decorrer da trienal, uma para cada ano da avaliação. Na última reclassificação do triênio foram avaliados dois mil, setecentos e nove periódicos.

De acordo com a classificação, a distribuição entre os estratos ficou da seguinte forma: no estrato A1 foram classificados 51 (2,24\%) periódicos, no estrato A2 foram classificados 75 $(3,29 \%)$ periódicos, no estrato B1 foram classificados $180(7,90 \%)$ periódicos, no estrato B2 foram classificados $93(4,08 \%)$ periódicos, no estrato B3 foram classificados $139(6,10 \%)$ periódicos, no estrato B4 foram classificados $126(5,53 \%)$ periódicos, no estrato B5 foram classificados $222(9,74 \%)$ periódicos e no estrato C foram classificados $(61,12 \%)$ periódicos. Se forem descontados os periódicos no estrato C (sem classificação), sobraram oitocentos e oitenta e dois periódicos que foram efetivamente considerados na última avaliação trienal a área de Direito.

A distribuição dos periódicos nos estratos ficou da seguinte forma: A1 51 (5,78\%); A2 75 (8,50\%); B1 180 (20,41\%); B2 93 (10,54\%) B3 135 (15,31\%); B4 $126(14,29 \%)$; B5 222 $(25,17 \%)$. Mesmo considerando somente os periódicos que foram classificados, verifica-se que a área do Direito ficou bem aquém do limite de ocupação dos periódicos mais elevados, notadamente os que estão nos estratos A1, A2 e B1.

Neste sentido, Maccari e Nishimura (2014, p. 613) destacam que o CTC define as seguintes travas para o povoamento desses estratos pelas áreas: (i) a quantidade de periódicos A1 deve ser inferior à quantidade de $\mathrm{A} 2(\mathrm{~A} 1<\mathrm{A} 2)$; (ii) a soma de periódicos A1 e A2 (A1+A2) tem que representar no máximo $25 \%$ do total dos periódicos qualificados da área; e (iii) a soma dos periódicos $\mathrm{A} 1, \mathrm{~A} 2, \mathrm{~B} 1(\mathrm{~A} 1+\mathrm{A} 2+\mathrm{B} 1)$ não pode ultrapassar $50 \%$ do total de periódicos classificados pela área. Assim, seguindo o que determina o CTC, a área do Direito poderia ter, no limite, $12 \%$ dos periódicos no estrato A1; $12,9 \%$ no estrato A2 e $25 \%$ no estrato B1, pois o somatório estes três estratos seria igual a 49,9\%, que é menor do que o somatório de B2 até B5. Pode se perceber a oportunidade perdida pela área do Direito devido à baixa ocupação dos estratos mais importantes. Neste caso, é importante se ter uma calibragem definida pela área $a$ priori de ocupação destes estratos.

A avaliação dos periódicos pela área do Direito levou em consideração os três últimos números de cada publicação até a data da classificação ou reclassificação. Os programas foram 
comunicados com antecedência para que enviassem informações detalhadas sobre os periódicos de seu interesse.

A partir dos dados informados pelos programas foi realizada a classificação dos periódicos. Para os periódicos não informados pelos programas de pós-graduação a Comissão Qualis realizou a coleta de dados e efetuou a classificação seguindo três momentos: a) verificação se o "periódico atinge os requisitos mínimos para ser considerado científico"; b) análise da "exogenia do conselho editorial, dos pareceristas ad hoc e dos autores dos artigos"; e, c) verificação do "impacto do periódico na área, a partir do cálculo do número de vezes que é citado em teses, dissertações e outros periódicos". A partir do cumprimento ou não desses requisitos foi realizada a classificação, em sentido crescente do estrato $\mathrm{C}$ para o estrato A1 dos periódicos (CAPES, 2013b).

O relatório de avaliação da trienal de 2013 (CAPES, 2013b) justifica que o grande número de periódicos classificados no estrato $\mathrm{C}$ decorre da exigência dos órgãos reguladores (MEC e OAB), ao longo da última década, exigir que cada curso de graduação em Direito possuísse a sua revista. Outra variável estaria no alto número de periódicos mantidos por "órgãos profissionais ligados à área" e que "não cumprem adequadamente os critérios da área para o seu posicionamento em estratos superiores ao $\mathrm{C}$, dadas as suas características de revistas de divulgação, com alta endogenia e pouca produção científica de alta qualidade".

Por fim, o relatório (CAPES, 2013b) informa que em comparação ao "povoamento atual dos estratos com o triênio anterior [...] um número expressivo de periódicos deixou o estrato C". Para a trienal de 2013 foram classificados oitocentos e oitenta e seis periódicos entre os estratos B5 a A1.

Após o levantamento de dados sobre a classificação de periódicos realizada pela área do Direito nos estratos A1, A2, B1, B2, B3, B4 e B5 relativo aos anos 2013 e 2014 (CAPES, 2016), o que se verifica é que nesses dois anos não houve um crescimento substancial no número de periódicos classificado em condições de atender a demanda de todos os programas de pósgraduação em Direito brasileiros. Por sua vez, da mesma forma, não houve crescimento substancial de periódicos de um ano para o outro entre os estratos e de um estrato para o outro.

A tabela a seguir, ilustra a ocupação dos estratos pela área nos anos de 2013 e 2014:

\begin{tabular}{|l|l|l|l|c|}
\hline \multirow{2}{*}{ Estrato } & \multicolumn{2}{|c|}{2013} & \multicolumn{2}{c|}{2014} \\
\cline { 2 - 5 } & \multicolumn{1}{|c|}{ Qtd } & $\%$ & \multicolumn{1}{c|}{ Qtd } & $\%$ \\
\hline A1 & 25 & $7,33 \%$ & 28 & $8,46 \%$ \\
\hline A2 & 41 & $12,02 \%$ & 41 & $12,39 \%$ \\
\hline B1 & 65 & $19,06 \%$ & 62 & $18,73 \%$ \\
\hline B2 & 55 & $16,13 \%$ & 44 & $13,29 \%$ \\
\hline B3 & 42 & $12,32 \%$ & 50 & $15,11 \%$ \\
\hline B4 & 44 & $12,90 \%$ & 43 & $12,99 \%$ \\
\hline B5 & 69 & $20,23 \%$ & 63 & $19,03 \%$ \\
\hline Total & 341 & $100,00 \%$ & 331 & $100,00 \%$ \\
\hline
\end{tabular}

Fonte: dos autores

Ao se analisar a tabela acima, verifica-se que houve uma diminuição dos periódicos classificados pela área do Direito nos anos de 2013 para 2014. Isto causa estranheza porque é de se esperar que novos periódicos entrem na base com o passar dos anos. Em relação à distribuição entre periódicos nacionais e estrangeiros classificados nos estratos nos anos de 2013 e 2014 foi a seguinte: 
Distribuição dos periódicos nacionais e estrangeiros (2013 e 2014):

\begin{tabular}{|l|l|l|l|c|}
\hline \multirow{2}{*}{ Estrato } & \multicolumn{2}{|c|}{2013} & \multicolumn{2}{c|}{2014} \\
\cline { 2 - 5 } & Nac. & Est. & Nac. & Est. \\
\hline A1 & $52 \%$ & $48 \%$ & $61 \%$ & $39 \%$ \\
\hline A2 & $46 \%$ & $54 \%$ & $46 \%$ & $54 \%$ \\
\hline B1 & $55 \%$ & $45 \%$ & $65 \%$ & $35 \%$ \\
\hline B2 & $78 \%$ & $12 \%$ & $80 \%$ & $20 \%$ \\
\hline B3 & $71 \%$ & $29 \%$ & $76 \%$ & $24 \%$ \\
\hline B4 & $86 \%$ & $14 \%$ & $91 \%$ & $9 \%$ \\
\hline B5 & $80 \%$ & $20 \%$ & $78 \%$ & $22 \%$ \\
\hline
\end{tabular}

Fonte: tabela dos autores

O que se percebe ao se analisar a tabela acima é que a área do direito os estratos mais elevados (A1, A2 e B1) existe uma ocupação ligeiramente superior dos periódicos editados no Brasil. Verifica-se que, em 2014, houve uma maior concentração dos periódicos brasileiros nestes estratos. Porém, ainda se observa um espaço importante para que mais periódicos ocupem estes estratos até os limites definidos pelo CTC e ilustrados na tabela anterior.

Outro ponto importante, é que quando a área cresce como um todo, ou seja, mais periódicos entram nos estratos de B2 a B5, abre-se espaço para mais periódicos ocuparem os estratos superiores. Neste sentido, é necessário que haja transparência na definição das regras para os periódicos porque assim a área pode se desenvolver de uma maneira consistente e contínua sem surpresas antes da avaliação.

Como a regra estabelecida é de que o periódico só pode subir ou descer um estrato a cada ano de avaliação naturalmente que nos dois últimos anos da avaliação quadrienal, 2015 e 2016, não haverá mudança significativa no número de periódicos entre os estratos. Principalmente nos estratos com pontuação mais representativa para os Programas de PósGraduação com conceitos 5 e 6 . Também o que se verifica é uma gradativa diminuição de periódicos internacionais nos estratos mais elevados podendo gerar impacto significativo na sustentação de programas de pós-graduação em conceitos 6 e, fundamentalmente, para que algum programa alcance o tão desejado conceito 7. Por outro lado, o que se destaca é que a quantidade de periódicos com Qualis de forte impacto na pontuação ainda não é significativa para absorver o conjunto de publicações que a área do Direito ainda demanda em capítulos ou coletâneas de livros.

\subsection{Classificação de Livros, Capítulos de Livros e Coletâneas}

De acordo com o relatório de avaliação da trienal de 2010 (CAPES, 2010b), a área do Direito classificou os livros, capítulos de livros e verbetes a partir da "inserção e coerência da produção dentro das linhas de pesquisa e áreas de concentração dos programas", seguindo uma hierarquia de pontuação decrescente entre os estratos L4, L3, L2 e L1 para cada item avaliado. A variação entre os estratos para os livros foi distribuída da seguinte forma: L4 - 100 pontos; L3 72 pontos; L2 - 52 pontos; e, L1 - 12 pontos. Os capítulos de livros foram pontuados da seguinte forma: L4 - 32 pontos; L3 - 24 pontos; L2 - 14 pontos; e, L1 - 4 pontos. Para a classificação de verbetes foi utilizada a pontuação de L4 - 32 pontos, L3 - 16 pontos, L2 - 6 e L1 - 2 pontos. Segundo o relatório, foram classificados aproximadamente dez mi, e duzentos itens entre livros, capítulos de livros e verbetes. 
Para a classificação de livros L4 foram levados em consideração os seguintes critérios: a) se "relato e/ou discussão de pesquisa focalizando questões teóricas e metodológicas, empíricas ou de aplicação"; b) "estudos e ensaios teóricos e debates conceituais"; c) "estudos e propostas de metodologias de pesquisa"; d) "estado da arte referente à determinada temática ou subárea de saber"; ou, e) "estudos, derivados de pesquisa, sobre metodologia para educação superior". De acordo com o relatório, para ser classificado no estrato L4, o livro deveria possuir "necessariamente, relevância, caráter inovador, potencial de impacto, esforço autoral e alcance teórico; organicidade" na estrutura interna da obra, "distribuição/circulação, qualidade da edição; e editora com conselho editorial". O livro deveria ainda se caracterizar como "acadêmico-didática ou de revisão de literatura com relevância, caráter inovador, potencial de impacto, esforço autoral e alcance teórico; organicidade, recorte autoral e abordagem aprofundada, alicerçada em trajetória de pesquisa nas áreas de conhecimento". Por fim, o livro seria valorizado se apresentasse os seguintes atributos: a) "financiamento da pesquisa"; b) "obra com até três autores"; c) "co-autoria com pesquisadores estrangeiros"; d) "pertencimento a coleções"; e) "avaliação por pares"; f) "apoio de agência para publicação (editais), prefácio e/ou apresentação de outro pesquisador e informação sobre o(s) autor(es) e prêmios” (CAPES, 2010b).

No estrato L3, foram incluídos os livros que atendiam parcialmente os critérios do estrato L4. Para o estrato L3, o critério "necessariamente" para a "relevância, caráter inovador, potencial de impacto, esforço autoral e alcance teórico, organicidade, distribuição/circulação, qualidade da edição" do livro, foi suprimido. Também para ser incluído no estrato L3, não se exigiu que o livro demonstrasse ter "esforço autoral, alcance teórico". Quanto aos atributos de valorização nesse estrato, o livro deveria possuir: a) "institucionalização da pesquisa no Programa, introdução/capítulos introdutório ou apresentação que [demostrasse] organicidade da obra"; b) "obra com até três autores"; c) "editora com conselho editorial e coleções"; d) "avaliação por pares"; e) "apoio de agência para publicação (editais)" (CAPES, 2010b).

Para o estrato L2, foram incluídos os livros que atendiam parcialmente os critérios do estrato L3, devendo a obra "apresentar organicidade". Nesse estrato, foram incluídas as obras acadêmico-didáticas ou de revisão de literatura que refletissem referência de "pesquisas e estudos na área educacional", que apresentassem organicidade. Como atributo de valorização das obras foram aplicados os critérios de: a) "ter até três autores"; b) "distribuição/circulação"; c) "qualidade da edição"; d) "editora com conselho editorial e coleções"; e e) "apoio de agência para publicação (editais) e prêmios" (CAPES, 2010b).

No estrato L1, foram classificadas as obras "com abordagem menos orgânica e pouca argumentação conceitual", sem a exigência de "ampla distribuição nacional” (CAPES, 2010b).

Para a classificação de coletâneas e dicionários, foi aplicada a mesma ordem decrescente de estratos utilizados para os livros: L4, L3, L2 e L1.

No estrato L4, foram classificadas as coletâneas que apresentavam "textos muito bem articulados cuja natureza [foi] relato e/ou discussão de pesquisa focalizando questões teóricas e metodológicas, empíricas ou de aplicação; estudos e ensaios teóricos e debates conceituais; estudos e propostas de metodologias de pesquisa; estado da arte referente à determinada temática ou subárea de saber; ou estudos, derivados de pesquisa, sobre metodologia de ensino para a educação superior". O relatório destaca que a obra deve "apresentar relevância, caráter inovador e potencial de impacto". Devendo, ainda, ser "necessariamente, produtos de convênios, de redes nacionais ou internacionais ou de pesquisa financiada". A obra passa a ser valorizada se apresenta os seguintes atributos: a) "participação discente"; b) "presença de autores e organizadores estrangeiros"; c) "ampla distribuição/circulação", d) "qualidade da edição"; e, e) "apoio de agência para publicação (editais) e prêmios” (CAPES, 2010b).

No estrato L3, foram incluídas as coletâneas que atendiam parcialmente os requisitos do estrato L4, além de representarem o resultado "de pesquisa institucional de grupos de pesquisa de um ou mais programas ou da consolidação de trajetórias de pesquisa dos autores". Ou, "coletânea 
com textos muito bem articulados cuja natureza [foi] revisão ou discussão de literatura, obra didática com revisão crítica da literatura sobre um tema, e biografia comentada ou apresentação da obra de um autor com seleção de textos e discussão crítica". Para o estrato L3, a valorização da obra levou em consideração os seguintes atributos: a) "participação discente"; b) "autores e organizadores estrangeiros"; b) "distribuição/circulação, qualidade da edição, apoio de agência para publicação (editais) e prêmios" (CAPES, 2010b).

No estrato L2, foram incluídas as coletâneas que apresentavam "textos com menor articulação" e que cumpriam os demais critérios previstos no estrato L3; porém, quanto aos atributos de valorização não apresentavam o "apoio de agência para a publicação (editais) e prêmios" (CAPES, 2010b).

No estrato L1, foram classificados os "textos pouco articulados, mas que [demonstravam] vinculação à pesquisa desenvolvida na instituição" (CAPES, 2010b).

A classificação de livros da trienal de 2010 ocorreu em três etapas. Na primeira etapa, foram estabelecidos os critérios para a classificação de todos os itens levando-se em consideração a "inserção" e a "coerência da produção" de acordo com as linhas de pesquisas e áreas de concentração do programa vinculado. Na segunda etapa, realizada entre março e maio de 2010, a comissão responsável "classificou as obras" dos anos de 2007, 2008 e 2009, indexadas nos cadernos de indicadores fornecidos pela CAPES. A terceira etapa, realizada no mês de maio de 2010, segundo o Relatório, "com a colaboração do CA INTER" e a partir de um "sistema criado pelo EGC/UFSC [...] os programas foram estimulados a incluírem os seus dados dentro do novo sistema, o que foi realizado por praticamente todos" (CAPES, 2010b).

O Relatório (CAPES, 2010b) não informa quantos Programas de Pós-Graduação enviaram os dados. A partir dessa etapa, todos os itens foram analisados "por uma Comissão de Avaliação", que levou em consideração "o limite de capítulos de livros de um mesmo programa por livro e autor". De acordo com o Relatório, "parcela importante da produção dos programas foi glosada nesta fase da classificação justamente por desatender a um ou outro critério". O Relatório não informa quantos itens foram glosados e nem qual foi o impacto sobre cada Programa de Pós-Graduação e para o conjunto da produção para a área do Direito. Por fim, o Relatório informa que "a pontuação da Classificação de livros foi atualizada de acordo com essa última triagem, o que permitiu que se considerasse de modo ainda mais preciso as informações prestadas pelos programas".

Em síntese, caso o Programa de Pós-Graduação, por alguma razão, não enviou os seus dados ou se os enviou de forma a não atender algum critério teve a sua produção glosada e, consequentemente, ficou sem a pontuação de direito. Nenhuma outra informação sobre o relatório de consolidação de livros, capítulos ou coletâneas foi prestada pelo Relatório 2010. Diante desse contexto, todos os Programas de Pós-Graduação envolvidos no processo de avaliação não tiveram acesso sobre a pontuação e a classificação da produção intelectual de seu corpo permanente.

Conforme Varella e Roesler (2012, p. 696), na trienal de 2010, "houve um esforço do comitê de classificação de livros para evitar abusos". Para os autores, foi possível detectar "casos de programas que publicavam livros, em gráficos, com artigos de todos os seus estudantes e professores, com três a quatro páginas cada, totalizando 30 a 40 artigos por obra. Algumas dessas coletâneas tiveram até 11 volumes no triênio, em livros com o mesmo título, variando apenas o ISBN”. Essa constatação, sem dúvida alguma, é grave; porém, estranho que tal informação não conste no Relatório para que toda a área tome conhecimento sobre o que não se deve fazer para burlar o sistema. Varela e Roesler ainda afirmam que o problema relatado "não se trata de uma situação isolada", só não informam quais os outros casos. O Relatório de 2010 também não informa situações atípicas ocorridas no decorrer da avaliação.

Para Varella e Roesler (2012, p. 696), com a utilização de critérios distintos da daqueles aplicados na trienal de 2007, principalmente limitando a "prática de coletâneas" e relacionando a 
produção do autor com as linhas e áreas do programa, foi possível reduzir em " $66 \%$ da pontuação total [de livros] da área de Direito". Com isso, o peso na trienal de 2010 da classificação de livros "foi de apenas 44\%" caso se mantivesse os critérios da trienal de 2007. Segundo os autores, "mesmo com a forte diminuição da pontuação em livros, coletâneas e capítulos de livros, o total de pontos obtidos foi de $73,24 \%$ do total", um pouco acima dos setenta por cento do total de pontos que se chegou na trienal de 2007.

Mesmo que se tenha aplicado uma calibragem mais rigorosa sobre livros, coletâneas e capítulos de livros na trienal de 2010, em relação à trienal de 2007, os autores não justificam as causas que levaram a pontuação total se manter na casa dos setenta por cento. Fica evidente que devido ao fato da área do Direito ter diminuído drasticamente a produção dos periódicos não classificando a grande maioria deles, ou mesmo diminuindo a nota dos que ela classificou, por mais que os livros, capítulos e coletâneas tiveram sua pontuação glosada, o seu peso na avaliação ainda foi substancial.

De acordo com o Relatório de 2013 (CAPES, 2013b), a área do Direito optou por classificar livros, capítulos e coletâneas pelo critério da "sua relevância como vínculo de publicação dos resultados da investigação científica dos programas de pós-graduação". O processo de classificação dos livros e coletâneas foi realizado em três etapas: a) Na primeira etapa, os Programas de Pós-Graduação enviaram exemplares de livros e coletâneas para a biblioteca de referência da área, sediada junto à Faculdade de Direito da Universidade Federal do Rio de Janeiro, juntamente com o preenchimento de informações complementares através de aplicativo próprio; b) Na segunda etapa, foi realizada a conferência da produção impressa com as informações contidas no aplicativo; e, c) Na última etapa, foi realizada a triagem e comparação da produção impressa e dados constantes no aplicativo de cada programa, com as informações prestadas através do sistema Coleta Capes.

O Relatório de 2013 (CAPES, 2013b) destaca que, a partir das informações prestadas pelos Programas de Pós-Graduação, os membros da comissão tiveram condições de "preparar a discussão presencial no Rio de Janeiro". Juntamente com as informações de dados de cada produção, como: "título, ISBN, autor(es), ficha catalográfica, sumário, introdução e informações adicionais sobre o vínculo com projetos e linhas de pesquisa, financiamento da pesquisa", foi sugerido aos Programas de Pós-Graduação enviarem "um dossiê sobre a sua produção em livros, coletâneas e capítulos de livros, com um detalhamento maior de seus vínculos com projetos de pesquisa e linhas de pesquisa, a fim de subsidiar a análise".

A partir das informações prestadas pelos programas de pós-graduação foram "produzidas planilhas específicas, por programa, para informar os consultores ad hoc que participariam da avaliação trienal a respeito da produção em livros, coletâneas e capítulos de livros". Segundo o Relatório, foram classificados dez mil, trezentos e setenta e cinco itens entre livros, capítulos e coletâneas. Para a classificação e pontuação desses itens levou-se em consideração o critério de aderência da publicação com as linhas e área(s) de concentração do programa ao qual o autor estava vinculado, seguindo uma hierarquia de pontuação decrescente entre os estratos L4, L3, L2 e L1 para cada item avaliado. A variação entre os estratos para os livros com texto integral seguiu de duzentos a cinquenta pontos. Para as coletâneas, a variação entre os estratos foi de cem a trinta e dois pontos e, para capítulos de livros, a variação entre os estratos foi trinta e dois a quatro pontos. Para cada estrato em cada item foram atribuídos requisitos de avaliação. A partir do cumprimento ou não dos requisitos o item recebeu o seu estrato (CAPES, 2013b).

Os requisitos para a classificação de livros no Relatório de 2013 (CAPES, 2013b), entre os estratos foram mantidos praticamente os mesmos dos critérios aplicados na trienal de 2010. Em cada estrato, foi incluído um novo critério objetivo; porém, ainda muito aberto e subjetivo no enquadramento de mérito de cada obra em particular. Para o estrato L4, segundo o Relatório, a obra deveria possuir "vinculação direta com a linha de pesquisa do programa a que [estivesse] 
vinculado o autor". Para a classificação no estrato L3, a obra deveria possuir "relação indireta com a linha de pesquisa do programa". Para a classificação no estrato L2, a obra deveria possuir "pouca relação com as linhas de pesquisa do programa". No estrato L1, foram classificadas as obras que trataram de "temas sem relação com as linhas de pesquisa do programa". No estrato LNC (livro não classificado), foram incluídos os livros que não cumpriram os critérios previstos pelos estratos.

A classificação das coletâneas do Relatório de 2013 (CAPES, 2013b) igualmente seguiu de forma geral os critérios aplicados na avaliação de coletâneas da trienal de 2010. No estrato L4, foi incluída a necessidade da coletânea apresentar "textos diretamente relacionados às linhas de pesquisa do programa". Os textos deveriam "estar muito bem articulados, preferencialmente com uma discussão entre os autores, revisão integral da obra por todos e existência de citações cruzadas no texto, de forma que [demonstrassem] o resultado de uma reflexão conjunta". Para o estrato, o Relatório recomenda "que a coletânea seja resultado de uma pesquisa coletiva e que tenha ocorrido um evento de debate entre os autores para revisão das posições, antes da publicação". No estrato L3, foi incluída a necessidade da coletânea apresentar "textos indiretamente relacionados com as linhas de pesquisa do programa e [textos] bem articulados". No estrato L2, foi incluída a necessidade da coletânea apresentar "textos com pouca relação com as linhas de pesquisa do programa". No estrato L1, foi incluída a possibilidade do artigo não possuir "relação com as linhas de pesquisa do programa". Já a coletânea que não apresentasse nenhum critério previsto pelos estratos estaria excluída de classificação.

Ao final, o Relatório informa que somente seriam considerados, "no máximo, dois capítulos de um mesmo autor na mesma coletânea e, no máximo, quatro capítulos do mesmo programa, na mesma coletânea". Havendo publicação de verbetes em dicionários, os mesmo seriam avaliados "de acordo com os critérios pertinentes às coletâneas" (CAPES, 2013b).

A partir da análise dos requisitos entre os estratos utilizados nas duas avaliações trienais (2010 e 2013) pode-se constatar por mais que os documentos de área tenham procurado estabelecer critérios quantitativos, a subjetividade é que prevalece na classificação da produção intelectual entre os estratos. No Relatório de 2013, percebe-se que houve uma preocupação em avaliar a produção intelectual a partir da aderência com as linhas e áreas de pesquisa do Programa de Pós-Graduação respectivo; no entanto, tal missão exigiria conhecimento específico e diversificado de todos os membros da Comissão de Classificação a fim de identificar em cada obra o cumprimento ou não de todos os critérios exigidos para cada estrato.

Conforme o Relatório de 2010, foram submetidos em torno de dez mil e duzentos itens de produção e para o Relatório de 2013 em torno de dez mil, trezentos e setenta e cinco itens. Tal quantidade de documentos exigiria tempo, treinamento, leitura atenda de cada documento e uma comissão de classificação ampla e em condições de efetuar análise de mérito para cada produção. Naturalmente que se estabelecer uma mera relação entre o título da obra com as linhas ou áreas de pesquisa do Programa de Pós-Graduação respectiva não representaria de fato a qualidade da produção.

Pelos Relatórios de 2010 (CAPES, 2010b) e 2013 (CAPES, 2013b), a produção deveria ser "relato e/ou discussão de pesquisa focalizando questões teóricas e metodológicas, empíricas ou de aplicação [...] se a obra apresenta relevância, caráter inovador, potencial de impacto, esforço autoral, abordagem aprofundada, qualidade da edição, circulação e alcance teórico". Naturalmente que para dimensionar esses critérios não basta a visualização da obra, seria necessário conhecimento sobre o conteúdo e se a mesma gerou ou não impacto para a área de conhecimento. Daí pode-se elaborar os seguintes questionamentos: como dimensionar tal impacto? Esse impacto deve se restringir ao número de exemplares impressos? Sobre a quantidade de citações no meio acadêmico? Sobre a quantidade de citações na esfera profissional ou judiciária? Qual o significado de obra inovadora? Como dimensionar se houve ou não esforço autoral ou abordagem aprofundada? Seria pela qualidade das fontes citadas? A qualidade da 
edição significaria "qualidade” gráfica de impressão? Por fim, como dimensionar a circulação ou o alcance teórico de cada produção intelectual? Tais dúvidas, em momento algum, os Relatórios tratam ou estabelecem a(s) metodologia(s) que seria(m) aplicada(s), no sentido de se ter a real dimensão de cada obra avaliada. Daí a prevalência de critérios subjetivos e meramente visuais das produções e não, efetivamente, qualitativos.

Por fim, destaca-se o importante levantamento realizado por Maccari e Nishimura (2014) sobre o povoamento dos estratos (conceitos dos Programas de Pós-Graduação brasileiros) de cada área de conhecimento consolidado pelas avaliações trienais de 2010 (CAPES, 2015b) e de 2013 (CAPES, 2015c) e, em especial, o resultado firmado para a área do Direito.

Concluída a avaliação trienal de 2010 (CAPES, 2015b), a distribuição de conceitos entre os estratos de todas as áreas do conhecimento ficou constituída da seguinte forma: 117 (4,3\%) programas obtiveram o conceito 7, $205(7,5 \%)$ programas obtiveram o conceito $6,556(20,5 \%)$ programas obtiveram o conceito $5,922(33,9 \%)$ programas obtiveram o conceito 4 e $858(31,6 \%)$ programas obtiveram o conceito 3 .

Ao final da avaliação trienal de 2013 (CAPES, 2015c), a distribuição de conceitos entre os estratos de todas as áreas do conhecimento ficou constituída da seguinte forma: 140 (4,2\%) programas obtiveram o conceito $7,266(8 \%)$ programas obtiveram o conceito $6,598(18 \%)$ programas obtiveram o conceito 5,1219 (36,5\%) programas obtiveram o conceito 4 e 1054 $(31,6 \%)$ programas obtiveram o conceito 3.

Após a avaliação trienal de 2013 das quarenta e oito áreas de conhecimento avaliadas pela CAPES, oito áreas não possuíam programas no povoamento do estrato de conceito 7 , dentre as quais está a área do Direito. Porém, a partir da análise do resultado da avaliação trienal de 2013 e tomando por base o crescimento e distribuição conceitual entre os estratos de todas as áreas de conhecimento, Maccari e Nishimura (2014) fizeram uma projeção de crescimento no povoamento dos estratos que não ocorreu para a área do Direito. Na trienal de 2013, foram avaliados setenta e quatro programas de pós-graduação em Direito, sendo que $31(41,9 \%)$ programas povoaram o conceito $3,25(33,8 \%)$ programas povoaram o conceito 4, $10(13,5 \%)$ programas povoaram o conceito 5 e $8(10,8 \%)$ povoaram o conceito 6 .

Seguindo a lógica proposta por Maccari e Nishimura (2014), na projeção de crescimento, levando em consideração o crescimento das demais áreas do conhecimento e o povoamento dos estratos por todas as áreas, a área do Direito na trienal de 2013 poderia ter sido composta da seguinte forma: $23(31,6 \%)$ programas povoando o conceito 3, $27(36,5 \%)$ programas povoando o conceito $4,14(18 \%)$ programas povoando o conceito 5, $6(8 \%)$ programas povoando o conceito 6 e $3(4,2 \%)$ programas povoando o conceito 7 . Desta forma, a área do Direito não destoaria da média de ocupação dos estratos percebido nas demais áreas.

Neste sentido, é inegável o avanço que a área do Direito vem alcançando avaliação após avaliação; porém, este reconhecimento por meio da ocupação dos estratos de avaliação mais elevados não está sendo verificado na prática. Outro ponto que merece realce é que a área do Direito é a décima quarta área em número de programas, das quarenta e oito que compõe o sistema de avaliação (CAPES, 2016).

Por fim, caberia para toda a área do Direito a disponibilidade em analisar com profundidade as causas que efetivamente comprometeram o crescimento quantitativo e qualitativo dos Programas de Pós-Graduação em Direito, conforme apontou Maccari e Nishimura (2014) em suas projeções. Nova avaliação, está prevista para o ano de 2017, agora sobre o quadriênio (2013, 2014, 2015 e 2016), e qualquer mudança de regras no que diz respeito à produção intelectual; nessa reta final, poderá comprometer novamente o tão desejado crescimento de toda a área. 


\section{CONCLUSÃO}

O objetivo central que envolveu a elaboração do presente a artigo foi o de verificar se os critérios qualitativos aplicados pela área do Direito na classificação que justificam a pontuação da produção intelectual do corpo permanente dos Programas de Mestrado e Doutorado reconhecidos pela CAPES reflete ou não o resultado quantitativo consolidado pelos relatórios finais das avaliações trienais de 2010 e 2013.

No decorrer do texto procurou-se destacar o significado e os elementos que envolvem a avaliação. Enfatizando que em todo processo de avaliação deve-se observar o compromisso com a clareza, transparência, objetividade, previsibilidade e envolvimento de todos os atores envolvidos. A avaliação não pode possuir caráter punitivo, o seu compromisso deve estar voltado para a verificação se as metas previamente estabelecidas foram ou não cumpridas.

Como forma de contextualizar a institucionalização do sistema de avaliação, o texto tratou de resgatar os aspectos formais e políticos que determinaram com que a CAPES se transformasse no único órgão público de controle de quantidade e de qualidade dos cursos de pós-graduação stricto sensu brasileiros.

O presente estudo se justificou na medida em que a própria CAPES estabelece, por meio do PNPG 2011- 2020, que os resultados das avaliações (trienais e/ou quadrienais) devem servir de base para a formulação de políticas públicas estratégicas para o desenvolvimento e fortalecimento do sistema de pós-graduação brasileiro.

Conforme os dados disponibilizados pela CAPES hoje existem quarenta e oito áreas de conhecimento, dentre as quais está a área do Direito. Conforme os dados coletados nos relatórios de área das avaliações trienais de 2010 e 2013, a área do Direito avaliou sessenta e três programas entre mestrados e doutorados e setenta e cinco programas entre mestrados e doutorados, respectivamente. $\mathrm{O}$ crescimento significativo da pós-graduação na área do Direito é uma realidade objetiva e concreta. Tal crescimento fica ainda mais evidente quando se observa a quantidade de programas reconhecidos pela CAPES até o mês de junho de 2016 que passa a ser de noventa e sete, entre mestrados acadêmicos, profissionais e doutorados.

Tomando por base os dados acima a conclusão que se chega é de que a área do Direito em termo quantitativos está em plena acessão. É nesse contexto que surge a necessidade urgente de se estabelecer métricas e instrumentos claros, objetivos, previsíveis e transparentes para se garantir a qualidade dos programas através do sistema avaliação. Na medida em que as métricas e instrumentos que serão aplicados na avaliação forem claros, consolidados e maduros cada programa individualmente poderá estabelecer a sua estratégia de planejamento e gestão.

No decorrer do nosso estudo ficou evidente que a área do Direito não possui critérios claros e definidos quando a previsibilidade na classificação e avaliação da produção intelectual do corpo permanente dos Programas de Pós-Graduação brasileiros. O relatório de avaliação da trienal de 2010 (envolvendo os anos de 2007, 2008 e 2009) relata que houve "uma revisão profunda e rigorosa do Qualis de todos os periódicos nacionais e estrangeiros classificados no sistema”. Nessa revisão, houve um rebaixamento dos periódicos A1 e A2 que passaram a ser reclassificados como B2. Os periódicos B1 foram reclassificados para B4 e os periódicos B2, B3 e B4 foram reclassificados para B5. Essa nova regra intempestiva e casuística foi aplicada para os anos 2007 e 2008. Já para o ano de 2009, a classificação e a avaliação levaram em consideração "critérios idênticos aos indexadores internacionais, com o indicativo da inclusão de todos os periódicos no scielo e em outros indexadores deste mesmo padrão". Em regra, para o ano de 2009, a área do Direito só considerou os periódicos que comprovassem double blind review. Após a aplicação desses novos critérios para a classificação dos periódicos, o resultado final foi profundamente impactante: menos de três por cento do total dos periódicos foram classificados em A1 e A2 e no estrato B1 foram classificados apenas seis por cento do total dos periódicos. Nesse percentual, praticamente só foram incluídos periódicos estrangeiros. Para a área do Direito, 
"a alteração na composição dos estratos foi significativa e observa-se um grande esforço de adaptação dos editores de periódicos e dos programas de pós-graduação, que deve render seus melhores frutos no próximo triênio" (CAPES, 2010b).

Para a trienal de 2010, o sistema Qualis registrava em torno de um mil e quatrocentos periódicos, entre nacionais e estrangeiros, com a aplicação de novas regras até então não definidas. Praticamente, mil periódicos foram descartados para o estrato C. Os periódicos que permaneceram entre os estratos B1 e A2 não representaram mais do que dez por cento do total, grande parte deles estrangeiros e com poucas produções de pesquisadores brasileiros. O impacto negativo sobre os programas com a aplicação de critérios não previstos anteriormente foi significativo. Sob o aspecto quantitativo, o número mais significativo da produção dos docentes dos programas brasileiros não foi considerado qualitativamente e descartadas para efeitos de avaliação. Nesse aspecto, pode-se concluir que o princípio da previsibilidade no processo de avaliação dos periódicos na trienal de 2010 não foi levado em consideração pela área do Direito,

$\mathrm{Na}$ trienal de 2013, percebemos que a área do Direito buscou estabelecer critérios mais objetivos na classificação dos periódicos. Porém, a insegurança no decorrer dos três anos avaliados continuou incerta e sem previsibilidade para o planejamento dos programas de pósgraduação. Apesar da área do Direito ter realizado reclassificações anuais, as incertezas quanto à progressão ou não nos estratos permaneceram incertas e imprevisíveis pela falta de definição de regras anteriores. A classificação se mantém dentro da lógica punitiva e não de autocorreção. $\mathrm{Na}$ trienal de 2013, foram classificados oitocentos e oitenta e seis periódicos entre os estratos A1 e B5 e oitocentos e oitenta e dois periódicos foram classificados no estrato $\mathrm{C}$, não gerando qualquer impacto qualitativo para a produção docente. A distribuição entre os estratos ficou consolidada da seguinte forma: 5,78\% em A1, 8,5\% em A2, 20,4\% em B1, 10,5\%, em B2, 15,3\% em B3, $14 \%$ em B4 e $25 \%$ em B5. Pelo número elevado de periódicos classificados, pode-se concluir que a ocupação de estratos mais elevados (A1, A2 e B1) ficou bem aquém da distribuição consolidada pela área do Direito. Considerando a quantidade de periódicos classificados e as regras estabelecidas pelo CTC/CAPES, a área do Direito poderia ter, no limite, $12 \%$ dos periódicos no estrato A1, 12,9\% no estrato A2 e $25 \%$ no estrato B1. A soma desses três estratos ficaria igual a $49,9 \%$, percentual menor da soma dos estratos B2 a B5.

Estrategicamente, ao não levar em consideração essa liberalidade concedida pelo CTC/CAPES, a área do Direito deixou de ocupar estratos superiores que poderiam reforçar o crescimento e o impacto qualitativo da produção dos pesquisadores e dos programas. Mais uma vez ficando claro que a área do Direito não possui estratégia e planejamento de avaliação de longo prazo. Na medida em que a área não estimula o crescimento qualitativo dos periódicos, o impacto se materializa ao final de cada avaliação trienal e agora quadrienal. Sem a existência de periódicos, principalmente nacionais, que consigam atender as demandas de todos os programas de pós-graduação brasileiros evidentemente que a área não terá consistência para crescer de forma sustentável.

No que diz respeito à classificação qualitativa de livros e capítulos de livros a insegurança, transparência e objetividade de critérios fica muito mais evidente. Cabe destacar que, pelo menos das duas últimas trienais, essa foi a modalidade de produção mais significativa de toda a área do Direito. Na trienal de 2010 foram submetidos em torno de 10.200 itens de produção para avaliação e na trienal de 2013 foram submetidos em torno de 10.375 itens. Evidentemente que avaliar qualitativamente em pouco tempo todos esses itens seria impossível. Diante desse quadro, a representação de área do Direito optou por uma calibragem mais rigorosa nos critérios para a classificação de livros e capítulos. Cabe esclarecer que essa calibragem não foi discutida anteriormente pelo conjunto da área. Para a avaliação desses itens novamente prevalece a concepção da avaliação punitiva. Por outro lado, o que se destaca entre as duas avaliações é que por mais que a área do Direito tenha tentando desestimular a publicação em livros e capítulos de livros as publicações nesses dois itens se mantiveram. Qual a razão? Não 
houve bom senso nos critérios de mobilidade entre os estratos dos periódicos e nem a compressão de que o CTC/CAPES liberaliza para as áreas de conhecimento algumas regras que cabe a cada área ajustar e calibrar. Infelizmente, a área do Direito, além de não utilizar tais regras ao seu favor, ainda realiza calibragens intempestivas, subjetivas e sem qualquer discussão prévia com os pares. A falta de planejamento e discussão com toda a área fica evidente a partir da análise dos dados da trienal de 2010 quando os periódicos foram sumariamente rebaixados sem que houvesse planejamento estratégico de crescimento para que os periódicos dos anos de 2010, 2011 e 2012 tivessem condições de atender as demandas de toda a área para a trienal de 2013.

Por fim, a conclusão que se chega é de que a falta de métricas e instrumentos objetivos para a análise de cada produção intelectual nas duas avaliações trienais (2010 e 2013) fica evidente não só pela inexistência de critérios efetivamente representativos de cada produção e transparência na divulgação das planilhas o que deixou cada programa sem informações essências para o estabelecimento de gestão e planejamento para as avaliações subsequente.

\section{REFERÊNCIAS BIBLIOGRÁFICAS}

BRASIL. Decreto $\mathrm{n}^{\circ}$ 50.737, de 07 de junho de 1961. Organiza a Campanha Nacional de Aperfeiçoamento de Pessoal de Nível Superior prevista pelo Decreto $n^{\circ} 29.741$, de 11 de julho de 1951. Disponível em: <http://www2.camara.leg.br/legin/fed/decret/1960-1969/decreto50737-7-junho-1961-390256-publicacaooriginal-1-pe.html>. Acesso em: 05 de novembro de 2015.

CAPES. Avaliação Trienal 2010. Brasília, 2010. Disponível em: <http://trienal.capes.gov.br/?page id=100>. Acesso em 09 de junho de 2016.

Caderno de Indicadores. Disponível em: <http://conteudoweb.capes.gov.br/conteudoweb/CadernoAvaliacaoServlet>. Acesso em 24 de junho de 2016.

- Resultado da Avaliação Trienal 2013 após Reconsideração. Brasília 2014. Disponível em: $\quad \quad$ http://www.avaliacaotrienal2013.capes.gov.br/home-page/noticiaspublicas/resultadofinaldaavaliacaotrienal2013-aposreconsideracao $>$. Acesso em 06 de junho de 2016.

Disponível

Dados Quantitativos de Programas Recomendados e Reconhecidos. Brasília, 2016. <https://sucupira.capes.gov.br/sucupira/public/consultas/coleta/programa/quantitativos/quantitati voAreaAvaliacao.jsf>. Acesso em 09 de junho de 2016.

. História e Missão. Disponível em: <http://www.capes.gov.br/sobre-a-capes/historia-emissao>. Acesso em 25 de julho de 2014.

. Documento de Área [do Direito] 2010a. Disponível em: <http://www.capes.gov.br>. Acesso em 25 de julho de 2014.

Relatório de Avaliação Trienal 2010b [Área do Direito]. Disponível em: <http://www.capes.gov.br>. Acesso em 25 de julho de 2014.

. Documento de Área [do Direito] 2013a. Disponível em: <http://www.capes.gov.br>. Acesso em 25 de julho de 2014.

Relatório de Avaliação Trienal 2013b [Área do Direito]. Disponível em: <http://www.capes.gov.br>. Acesso em 25 de julho de 2014.

Plataforma Sucupira. Disponível em: <https://sucupira.capes.gov.br/sucupira>. Acesso em: 20 de novembro de 2015. 
- Relatório de Gestão do Exercício de 2014. Disponível em: <http://www.capes.gov.br/images/stories/download/Contas Publicas/2014 Relatorio de Gest ao CAPES.pdf $>$. Acesso em: 15 de outubro de 2015a.

. Resultados finais: Trienal 2010. Disponível em: <http://trienal.capes.gov.br/?page $\mathrm{id}=100>$. Acesso em 20 de nov. $2015 \mathrm{~b}$.

. Resultados Avaliação Trienal 2013 - Planilha de Notas. 2013c. Disponível em: $\langle$ http://avaliacaotrienal2013.capes.gov.br/resultados/planilha-de-notas〉. Acesso em 25 de nov. 2015 c.

. Resultados Avaliação Trienal 2013 - Apresentação dos Resultados. Disponível em: $\langle$ http://avaliacaotrienal2013.capes.gov.br/resultados/planilha-de-notas〉. Acesso em 22 de nov. de 2015d.

. Avaliação. Disponível em: 〈http://www.capes.gov.br/avaliacao〉. Acesso em: 10 de fevereiro de 2016a.

Periódicos Qualis. Disponível em: <https://sucupira.capes.gov.br/sucupira/public/consultas/coleta/veiculoPublicacaoQualis/listaC onsultaGeralPeriodicos.jsf $>$. Acesso em: 19 de março de 2016.

CIMADON, Aristides. Ensino e aprendizagem na Universidade - Um Roteiro de Estudo. 3. ed. Florianópolis: Conceito, 2008.

DEMO, Pedro. Pesquisa e informação qualitativa - Aportes Metodológicos. Campinas: Papirus, 2001.

FOUCAULT, Michel. Vigiar e punir: Nascimento da Prisão. 2. ed. Petropolis: Vozes, 1983.

GOMES NETO, J. B.; ROSENBERG, L. Indicadores de Qualidade do Ensino e seu Papel no Sistema Nacional de Avaliação. Em aberto. Brasília, n.66, p. 13- 28, abr./jun. 1995.

MACCARI, E. A. Contribuição à Gestão dos Programas de Pós-graduação Stricto Sensu em Administração no Brasil com Base nos Sistemas de Avaliação Norte-Americanos e Brasileiro. Tese de doutorado. Faculdade de Economia Administração e Contabilidade da Universidade de São Paulo, São Paulo, 2008.

. Povoamento dos Estratos pelas Áreas na Capes. Palestra proferida em 05 de junho de 2015 no XXIV Encontro Nacional do CONPEDI, realizado na cidade de Aracajú - Sergipe, no painel Transparência nas Informações: Sucupira do Direito, 2015.

MACCARI, E. A.; ALMEIDA, Martinho Isnard Ribeiro de; NISHIMURA, A. T.; RODRIGUES, L. C. A Gestão dos Programas de Pós-Graduação em Administração com Base no Sistema de Avaliação da CAPES. REGE. Revista de Gestão USP, v. 16, p. 1-16, 2009.

MACCARI, E. A.; NISHIMURA, A. T. Povoamento Estratos Conceitos 6 e 7 no Sistema de Avaliação da CAPES pela Área de Administração, Ciências Contábeis e Turismo nas Avaliações Trienais 2010 e 2013. READ. Porto Alegre, v. 79, n. 3, p. 601-624, setembro/dezembro 2014. 
UNESCO. La Educación Superior em El Siglo XXI. Visión y acción. Conferencia Mundial sobre La Educación Superior. Paris, 1998.

VARELA, Marcelo Dias; ROESLER, Cláudia Rosane. Dificuldades de Avaliação de Publicações na Área de Direito. RBPG. Brasília, v. 9, n. 18, p. 663-701, dezembro de 2012.

VERHINE, R. E.; FREITAS, Antônio Alberto da Silva Monteiro de. A Avaliação da Educação Superior: Modalidades e Tendências no Cenário Internacional-Melhor Caminho é Integração e Complementariedade da Avaliação Externa, Padronizada, e a Interna, que Respeita Diversidade Institucional. Revista Ensino Superior Unicamp. V. 3, n. 7, p. 16-39, 2012. 